Correspondence

Paula Tamagnini

pmtamagn@ibmc.up.pt

Received 22 June 2011

Revised 10 October 2011

Accepted 10 November 2011

\section{Construction of a chassis for hydrogen production: physiological and molecular characterization of a Synechocystis sp. PCC 6803 mutant lacking a functional bidirectional hydrogenase}

\author{
Filipe Pinto, ${ }^{1,2}$ Karin A. van Elburg, ${ }^{3}$ Catarina C. Pacheco, ${ }^{1}$ Miguel Lopo, ${ }^{1}$ \\ Josselin Noirel, ${ }^{3}$ Arnau Montagud, ${ }^{4}$ Javier F. Urchueguía, ${ }^{4}$ \\ Phillip C. Wright ${ }^{3}$ and Paula Tamagnini ${ }^{1,2}$ \\ ${ }^{1}$ IBMC - Instituto de Biologia Molecular e Celular, Universidade do Porto, \\ Rua do Campo Alegre 823, 4150-180 Porto, Portugal \\ ${ }^{2}$ Faculdade de Ciências, Departamento de Biologia, Universidade do Porto, Rua do Campo Alegre, \\ Edifício FC4, 4169-007 Porto, Portugal \\ ${ }^{3}$ Biological and Environmental Systems Group, ChELSI Institute, Department of Chemical and \\ Biological Engineering, University of Sheffield, Mapping Street, Sheffield S1 3JD, UK \\ ${ }^{4}$ Instituto Universitario de Matemática Pura y Aplicada, Universidad Politécnica de Valencia, \\ Camí de Vera, E-46071 Valencia, Spain
}

\begin{abstract}
Cyanobacteria are photosynthetic prokaryotes that are promising 'low-cost' microbial cell factories due to their simple nutritional requirements and metabolic plasticity, and the availability of tools for their genetic manipulation. The unicellular non-nitrogen-fixing Synechocystis sp. PCC 6803 is the best studied cyanobacterial strain and its genome was the first to be sequenced. The vast amount of physiological and molecular data available, together with a relatively small genome, makes Synechocystis suitable for computational metabolic modelling and to be used as a photoautotrophic chassis in synthetic biology applications. To prepare it for the introduction of a synthetic hydrogen producing device, a Synechocystis sp. PCC 6803 deletion mutant lacking an active bidirectional hydrogenase $(\triangle h \circ \times Y H)$ was produced and characterized at different levels: physiological, proteomic and transcriptional. The results showed that, under conditions favouring hydrogenase activity, 17 of the 210 identified proteins had significant differential fold changes in comparisons of the mutant with the wild-type. Most of these proteins are related to the redox and energy state of the cell. Transcriptional studies revealed that only six genes encoding those proteins exhibited significant differences in transcript levels. Moreover, the mutant exhibits similar growth behaviour compared with the wild-type, reflecting Synechocystis plasticity and metabolic adaptability. Overall, this study reveals that the Synechocystis $\Delta$ hox $Y H$ mutant is robust and can be used as a photoautotrophic chassis for the integration of synthetic constructs, i.e. molecular constructs assembled from well characterized biological and/or synthetic parts (e.g. promoters, regulators, coding regions, terminators) designed for a specific purpose.
\end{abstract}

\section{INTRODUCTION}

Cyanobacteria are photosynthetic prokaryotes that are able to perform oxygenic photosynthesis, using water as an electron donor. They constitute one of the largest and most remarkable groups of bacteria on Earth, playing a key role in

Abbreviations: FDR, false discovery rate; RT-qPCR, real time quantitative PCR.

A set of supplementary methods, four supplementary figures and two supplementary tables are available with the online version of this paper. both the carbon and the nitrogen cycle (Bothe et al., 2010b; Moisander et al., 2010). Cyanobacteria are a prolific source of bioactive compounds (Burja et al., 2001; Dembitsky, 2006), they have been used as biofertilizers and food supplements, and their strong potential in the fields of energy, bioremediation, bioplastics and medical diagnostics has been reported (Abed et al., 2009; Devillers et al., 2007). The simple nutritional requirements of these organisms, combined with their autotrophy and metabolic plasticity, as well as the availability of molecular tools for their genetic manipulation, makes them promising 'low-cost' microbial 
cell factories (Abed et al., 2009; Thajuddin \& Subramanian, 2005).

Synthetic biology applies the standardization and hierarchical abstraction of engineering to biological systems, in order to redesign existing systems or design entirely new ones (Bashor et al., 2010; Endy, 2005; Khalil \& Collins, 2010; Yadav \& Stephanopoulos, 2010). Following this philosophy, the BioModularH $\mathrm{H}_{2}$ project (www.biomodularh2.org) aimed at designing and constructing molecular parts/modules/ devices that, once integrated into a cyanobacterial chassis, will redirect metabolic fluxes towards efficient hydrogen production. For this purpose, the unicellular non- $\mathrm{N}_{2}-$ fixing Synechocystis sp. PCC 6803 (hereafter referred to as Synechocystis) was chosen as the chassis. Biological chassis should be robust and well characterized organisms preferably capable of growing on minimal, inexpensive carbon sources considering their use for laboratory- or large-scale production of the desired molecule(s). Nonetheless, even in most robust hosts/chassis, foreign DNA instability can pose a problem, due to their ability to inactivate or dispose of the foreign genes (Keasling, 2008). In Escherichia coli this issue has been addressed by removing large sections of the chromosome, some containing mobile elements and cryptic virulence genes (Pósfai et al., 2006; Sharma et al., 2007a, b). Additionally, the presence of genes encoding proteins that may interfere and/or compete with those introduced should be eliminated. In this context, Synechocystis is a photoautotrophic organism with minimal nutritional requirements that uses $\mathrm{CO}_{2}$ and sunlight as sources of carbon and energy. Its genome, the first to be sequenced among cyanobacteria, comprises a $3.6 \mathrm{Mb}$ chromosome and seven plasmids (Kaneko et al., 1996, 2003; Xu \& McFadden, 1997; Yang \& McFadden, 1993, 1994). This strain became the most studied cyanobacterium, for which plenty of physiological and molecular information is now available (Barrios-Llerena et al., 2006; Bhaya et al., 2000; Koksharova \& Wolk, 2002; Ow \& Wright, 2009; Schmitt \& Stephanopoulos, 2003; Suzuki et al., 2006; Zhang et al., 2008). Moreover, it is naturally transformable with exogenous DNA, and a variety of molecular tools have been developed for its genetic manipulation. The vast amount of data, together with a relatively small genome, makes Synechocystis suitable for computational metabolic modelling and to be used as a photoautotrophic chassis.

Taking into account the aim of the BioModular $\mathrm{H}_{2}$ project, and since a heterologous hydrogenase (hydrogen producing device) was going to be introduced, the native bidirectional hydrogenase of Synechocystis became a redundant part, and therefore should be removed. It has been reported that the bidirectional hydrogenase of Synechocystis could be involved in dark fermentation, act as an electron valve during photosynthesis, or even be part of the respiratory complex I (Antal \& Lindblad, 2005; Appel \& Schulz, 1996; Appel et al., 2000; Gutthann et al., 2007; Troshina et al., 2002). The bidirectional hydrogenase of Synechocystis has been recently characterized as a truly bidirectional enzyme with a bias to $\mathrm{H}_{2}$ production (McIntosh et al., 2011); however, further investigation is needed to clarify the role of this type of enzyme (Angermayr et al., 2009; Bothe et al., 2010a; Carrieri et al., 2011; McIntosh et al., 2011; Oliveira, 2008; Tamagnini et al., 2002, 2007). In this work, a Synechocystis deletion mutant $(\Delta h o x Y H)$, lacking an active bidirectional hydrogenase and without any selection marker, was produced and characterized. In addition, a strategy to construct vectors compatible with the BioBrick system (http://partsregistry. org/Main_Page) was developed to efficiently remove redundant genes and/or introduce DNA-based synthetic parts and circuits into the Synechocystis genome. The molecular tools (BioBrick compatible integrative vectors) and the photoautotrophic chassis produced in this work can be easily extended to other biotechnological applications aiming to exploit a light-driven biological system.

\section{METHODS}

Organisms and standard growth conditions. The unicellular non$\mathrm{N}_{2}$-fixing cyanobacterium Synechocystis sp. PCC 6803 (obtained from the Pasteur Culture Collection, Paris, France) was maintained in BG11 medium (Stanier et al., 1971) at $25^{\circ} \mathrm{C}$ and $12 \mathrm{~h}$ light $(20 \mu \mathrm{E}$ $\mathrm{m}^{-2} \mathrm{~s}^{-1}$ with Osram L18W/765 cool white daylight bulbs)/12 h dark cycles, unless stated otherwise. Cosine-corrected irradiance was measured by using a quantum meter (Skye SKP 216 Quantum sensor with SKP 200 Measuring unit, Hansatech Instruments). For solid medium, BG11 was supplemented with $1.5 \%$ Noble agar (Difco), $0.3 \%$ sodium thiosulfate and $10 \mathrm{mM}$ TES-KOH buffer ( $\mathrm{pH} 8.2$ ). For the selection of the mutants, BG11 medium was supplemented with kanamycin $\left(\mathrm{Km}, 10-50 \mu \mathrm{g} \mathrm{m}{ }^{-1}\right)$ or sucrose $[10 \%(\mathrm{w} / \mathrm{v})]$. For the proteomics analysis, standard growth conditions were used, with a scalar irradiance of $75 \mu \mathrm{E} \mathrm{m} \mathrm{m}^{-2} \mathrm{~s}^{-1}$ (measured with a QSL-2100 Radiometer, Biospherical Instruments, and equivalent to the standard growth light intensity described above). Anaerobic conditions were induced by sparging with argon for $30 \mathrm{~min}$ in the dark. Cells were then kept in the dark for $2 \mathrm{~h}$ before being harvested. E. coli DH5 $\alpha$ (Stratagene) was used for cloning purposes. E. coli transformants were cultivated at $37{ }^{\circ} \mathrm{C}$ in Luria-Bertani (LB) medium supplemented with $100 \mu \mathrm{g}$ ampicillin $\mathrm{ml}^{-1}$ or $50 \mu \mathrm{g}$ kanamycin $\mathrm{ml}^{-1}$.

DNA extraction and recovery. Cyanobacterial genomic DNA was extracted using the phenol/chloroform method described previously (Tamagnini et al., 1997). Agarose gel electrophoresis was performed by standard protocols using $1 \times$ TAE buffer (Sambrook \& Russell, 2001), and the DNA fragments were isolated from gels using the GFX PCR DNA and Gel Band Purification kit (GE Healthcare), according to the manufacturer's instructions.

Plasmid construction. The plasmids used in this work, pGDYH and pGDYH.NS, were based on pGEM-T Easy (Promega) and contain the Synechocystis chromosomal regions flanking the hoxYH genes (encoding subunits of the bidirectional hydrogenase). The regions upstream from hoxY and downstream from hoxH were amplified by PCR using primers with tags containing restriction sites for cloning purposes (Table 1). Additionally, the primers 5-I and 3-I contain sites compatible with the BioBrick system: MunI, XbaI, SpeI and PstI. Each PCR mixture $(50 \mu \mathrm{l})$ contained $1.5 \mathrm{U}$ Pfu DNA polymerase (Fermentas), $1 \times$ reaction buffer $[10 \times$ reaction buffer: $200 \mathrm{mM}$ Tris/ $\mathrm{HCl} \mathrm{pH} \mathrm{8.8,} 100 \mathrm{mM}\left(\mathrm{NH}_{4}\right)_{2} \mathrm{SO}_{4}, 100 \mathrm{mM} \mathrm{KCl}, 1 \mathrm{mg} \mathrm{BSA} \mathrm{ml}{ }^{-1}, 1 \%$ (v/v) Triton X-100, $20 \mathrm{mM} \mathrm{MgSO} 4$ ], $250 \mu \mathrm{M}$ of each deoxyribonucleotide triphosphate, $200 \mathrm{nM}$ each primer (primer pairs 5-O/5-I or 3O/3-I) and 7 ng Synechocystis genomic DNA. The PCR profile was 2 min at $95{ }^{\circ} \mathrm{C}$ followed by 35 cycles of $30 \mathrm{~s}$ at $95{ }^{\circ} \mathrm{C}, 45 \mathrm{~s}$ at $60{ }^{\circ} \mathrm{C}$ and 
Table 1. Oligonucleotide primers used in this study

\begin{tabular}{|c|c|c|}
\hline Name & Sequence $\left(5^{\prime}-3^{\prime}\right)$ & Purpose \\
\hline $5-\mathrm{O}^{*}$ & GAAGCCCGGGTTCCCATTCCCACCCTTTGCCATTTAG & Mutant construction/Southern probe \\
\hline $5-I^{*}$ & $\frac{\text { CTGCAGACTAGTACGACCTTCTAGACAATTGGAGCCA }}{\text { TTCGTCCATATCAAGGAAGGACATATGACAGC }}$ & Mutant construction/Southern probe \\
\hline $3-\mathrm{O}^{*}$ & TAGTAAGCTTGCCTTTGATAACCACAGTGCCCAG & Mutant construction \\
\hline $3-I^{*}$ & $\frac{\text { CAATTGTCTAGAAGGTCGTACTAGTCTGCAGCC }}{\text { TGCCTTAGTTGTTCTACCCATGCAGCGGGACAAATG }}$ & Mutant construction \\
\hline FO & AGAATATTGGATTGTGGATGTGAAGGC & Mutant confirmation \\
\hline RO & CAGGGAGTGGAGTTAATTAGAACAGG & Mutant confirmation \\
\hline NeosacB2F* & GCTGGAATTCAGGAAGCGGAACACGTAGAAAG & Selection cassette amplification \\
\hline NeosacB3R ${ }^{*}$ & CTACCAATTGCGTAACAGATGAGGGCAAGCGGATGG & Selection cassette amplification \\
\hline U.atpC_2F & CTAGTGGCTCTATTCGTATC & RT-qPCR \\
\hline U.atpC_2R & ATAACTGGTTGGTGTTGTAC & RT-qPCR \\
\hline U.lexA_F & GGTTACGCAATAAGG & RT-qPCR \\
\hline U.lexA_R & AGAACGGAGAATCAG & RT-qPCR \\
\hline U.lrtA_F & GAAGACAAGCCAGTG & RT-qPCR \\
\hline U.lrtA_R & TGAATAACGCCATAGC & RT-qPCR \\
\hline U.petB_2F & TCAATGGTTCAATGATCGTC & RT-qPCR \\
\hline U.petB_2R & CATGATGTATTGGACAGAGG & RT-qPCR \\
\hline U.psbY_F & ATTGGCGTGTAATTGTAG & RT-qPCR \\
\hline U.psbY_R & AACGTCCTGTAACTGC & RT-qPCR \\
\hline U.rplK_F & GATGATTATTCCTGTGG & RT-qPCR \\
\hline U.rplK_R & GTCGTTGGCATTAAG & RT-qPCR \\
\hline U.sodB_F & CGCTGACTTTGGTAG & RT-qPCR \\
\hline U.sodB_R & TCGGCAATGTAATCG & RT-qPCR \\
\hline U.trxA_F & TTAGACAGCGAGTTAC & RT-qPCR \\
\hline U.trxA_R & САССАССАТАТССАС & RT-qPCR \\
\hline U.tufA_F & GAATTGGTGGAACTG & RT-qPCR \\
\hline U.tufA_R & GTGATGGAGAATACG & RT-qPCR \\
\hline D.ppa_2F & TAAATACGAGTTCGACAAAG & RT-qPCR \\
\hline D.ppa_2R & TCAATCATTTCCAACATACC & RT-qPCR \\
\hline D.pgk_2F & GAATTACAGTTCCTCCAAGG & RT-qPCR \\
\hline D.pgk_2R & AGTCCAATTTGTCTTCTTCC & RT-qPCR \\
\hline D.slr2025_F & CAAGATAACGACCAG & RT-qPCR \\
\hline D.slr2025_R & GAGAGCCACTAAATG & RT-qPCR \\
\hline BD16SF1† & CACACTGGGACTGAGACAC & RT-qPCR \\
\hline BD16SR1† & CTGCTGGCACGGAGTTAG & RT-qPCR \\
\hline
\end{tabular}

${ }^{\star}$ Restriction enzyme recognition sites are underlined.

$\dagger$ Ferreira et al. (2009).

$2.5 \mathrm{~min}$ at $72{ }^{\circ} \mathrm{C}$, and a final extension at $72{ }^{\circ} \mathrm{C}$ for $7 \mathrm{~min}$. The two purified PCR fragments were fused by 'overlap-PCR', and the reaction mixture $(50 \mu \mathrm{l})$ contained $1.25 \mathrm{U}$ Taq polymerase (GE Healthcare), $1 \times$ reaction buffer $(10 \times$ reaction buffer: $100 \mathrm{mM}$ Tris $/ \mathrm{HCl} \mathrm{pH} 9.0$, $15 \mathrm{mM} \mathrm{MgCl} 2$ and $500 \mathrm{mM} \mathrm{KCl}$ ), $250 \mu \mathrm{M}$ of each deoxyribonucleotide triphosphate, $0.2 \mu \mathrm{g} \mathrm{BSA} \mu \mathrm{l}^{-1}, 130 \mathrm{nM}$ each outer primer (5-O and 3-O) and 80 ng each purified DNA fragment. The PCR profile was 5 min at $95{ }^{\circ} \mathrm{C}$ followed by 35 cycles of $30 \mathrm{~s}$ at $95{ }^{\circ} \mathrm{C}, 45 \mathrm{~s}$ at $60{ }^{\circ} \mathrm{C}$ and $1.75 \mathrm{~min}$ at $72{ }^{\circ} \mathrm{C}$, and a final extension at $72{ }^{\circ} \mathrm{C}$ for $10 \mathrm{~min}$. The resulting product was purified and cloned into the vector pGEM-T Easy, according to the manufacturer's instructions, producing the pGDYH plasmid. A selection cassette, containing the nptII gene (conferring resistance to neomycin and kanamycin) and the $s a c B$ gene (sucrose sensitivity), was amplified by PCR from the plasmid pK18mobsacB (Schäfer et al., 1994), using the primer pair NeosacB2F and NeosacB3R. The PCR mixture $(20 \mu \mathrm{l})$ contained $0.5 \mathrm{U}$ Taq polymerase (GE Healthcare), $1 \times$ reaction buffer $(10 \times$ reaction buffer is $100 \mathrm{mM}$ Tris/ $\mathrm{HCl} \mathrm{pH} 9.0,15 \mathrm{mM} \mathrm{MgCl}_{2}$ and $500 \mathrm{mM} \mathrm{KCl}$ ), $200 \mu \mathrm{M}$ of each deoxyribonucleotide triphosphate, $1 \mu \mathrm{M}$ of each primer and $3 \mathrm{ng}$ of each purified DNA fragment. The PCR profile was: $2 \mathrm{~min}$ at $95{ }^{\circ} \mathrm{C}$ followed by 40 cycles of $30 \mathrm{~s}$ at $95{ }^{\circ} \mathrm{C}$, $30 \mathrm{~s}$ at $60{ }^{\circ} \mathrm{C}$ and $3 \mathrm{~min}$ at $72{ }^{\circ} \mathrm{C}$ and a final extension at $72{ }^{\circ} \mathrm{C}$ for $7 \mathrm{~min}$. The purified PCR fragment was cloned into pGEM-T Easy, and the resulting vector was digested with EcoRI and MunI restriction enzymes (Fermentas), according to the manufacturer's instructions. Subsequently, the purified DNA fragment containing the selection cassette was cloned in the MunI restriction site of pGDYH, using the T4 DNA ligase (Fermentas) to form the plasmid pGDYH.NS. All the constructs were confirmed by DNA sequencing (STAB VIDA).

Generation of the Synechocystis sp. PCC 6803 hoxYH deletion mutant. Synechocystis was transformed using a method based on a procedure described by Williams (1988). Briefly, Synechocystis cultures were grown in BG11 medium at $30{ }^{\circ} \mathrm{C}$, under continuous 
light $\left(20 \mu \mathrm{E} \mathrm{m}^{-2} \mathrm{~s}^{-1}\right)$, to $\mathrm{OD}_{730} \sim 0.5$. Cells were harvested by centrifugation and resuspended in 1/10 volume of BG11. A $100 \mu \mathrm{l}$ sample of these cells was incubated with the purified pGDYH.NS plasmid for $5 \mathrm{~h}$, in light at room temperature, with a final plasmid DNA concentration of $6-20 \mu \mathrm{g} \mathrm{ml}^{-1}$. Cells were then spread onto Immobilon-NC membranes $(0.45 \mu \mathrm{m}$ pore size, $82 \mathrm{~mm}$, Millipore $)$ resting on solid BG11 plates, grown at $30{ }^{\circ} \mathrm{C}$ under continuous light, and were transferred to selective plates containing $10 \mu \mathrm{g}$ kanamycin $(\mathrm{Km}) \mathrm{ml}^{-1}$ after $24 \mathrm{~h}$. Transformants were observed after 1-2 weeks. For complete segregation, Km-resistant colonies were grown at increasing $\mathrm{Km}$ concentrations (25 and $50 \mu \mathrm{g} \mathrm{ml}^{-1}$ ) and finally transferred into liquid medium. Mutants were then tested for sucrose sensitivity, and confirmed by PCR and Southern blot with a probe labelled with digoxigenin using the DIG DNA labelling kit (Roche Molecular Biochemicals) (Fig. 1). Subsequently, to remove the selection markers from the disruption mutant, cells were transformed as described above with the vector pGDYH, and the mutants were selected in solid BG11 containing $10 \%$ sucrose (w/v). These mutants were also screened for $\mathrm{Km}$-sensitivity, and the full segregation was confirmed by PCR using primers external to the insertion sites (FO and RO, Table 1) and by Southern blot (Fig. 1). Southern blot was performed using genomic DNA that was digested with HindIII or HincII, and a probe covering the $5^{\prime}$ flanking region of hoxYH genes (amplified by PCR using the primer pair 5-O and 5-I). A representative diagram of the mutant construction is depicted in Fig. 2. Moreover, the presence/absence of an active bidirectional hydrogenase in the wild-type and $\Delta$ hox $Y H$ mutant was assessed by gas chromatography after placing the cells in dark and replacing air with argon.

Growth experiments. Cultures of Synechocystis wild-type and $\Delta$ hoxYH mutant were grown to $\mathrm{OD}_{730} \sim 1.0$, and $24 \mathrm{~h}$ before the beginning of the experiment, were transferred to fresh BG11 medium. Inocula of $200 \mu \mathrm{l}$ were then added to sterile $4.5 \mathrm{ml}$ cuvettes containing $1800 \mu \mathrm{l}$ medium with or without $5 \mathrm{mM}$ glucose and given concentrations of nitrate $\left(0.1\right.$ or $\left.1.5 \mathrm{~g} \mathrm{l}^{-1}\right)$. Each experiment was performed in triplicate and under aseptic conditions. The cuvettes were closed with sterilized Parafilm and placed in acrylic racks specially designed for this experiment. The racks were placed in a chamber with constant temperature $\left(25^{\circ} \mathrm{C}\right)$, under continuous light $\left(20 \mu \mathrm{E} \mathrm{m}^{-2} \mathrm{~s}^{-1}\right)$ or a $12 \mathrm{~h}$ light $\left(20 \mu \mathrm{E} \mathrm{m}^{-2} \mathrm{~s}^{-1}\right) / 12 \mathrm{~h}$ dark regimen, and the $\mathrm{OD}_{730}$ was recorded daily.

Statistical analysis of the specific growth. The quantitative analysis of Synechocystis wild-type and $\Delta$ hoxYH mutant growth in various conditions was based on the optical density measurements (see above). For each bin, $i$, a specific growth parameter, representing the exponent of (assumed) exponential growth within the given time interval was calculated as

$\mu_{i}=\frac{\log \left(x_{i+1} / x_{i}\right)}{t_{i+1}-t_{i}}$

where $t_{i}$ is time, in units of days running from day 0 to $t_{i \max }$, and $x_{i}$ is the corresponding measured optical density.

In order to work with a statistic that does not depend rather arbitrarily on test duration, particularly if under some particular conditions stationary growth is reached sooner than in others, we chose not to work with the mean specific growth rate but rather the maximum specific growth rate:

$$
\mu_{\max }=\left.\max \left(\mu_{i}\right)\right|_{i=0, \ldots, i_{\max }}
$$

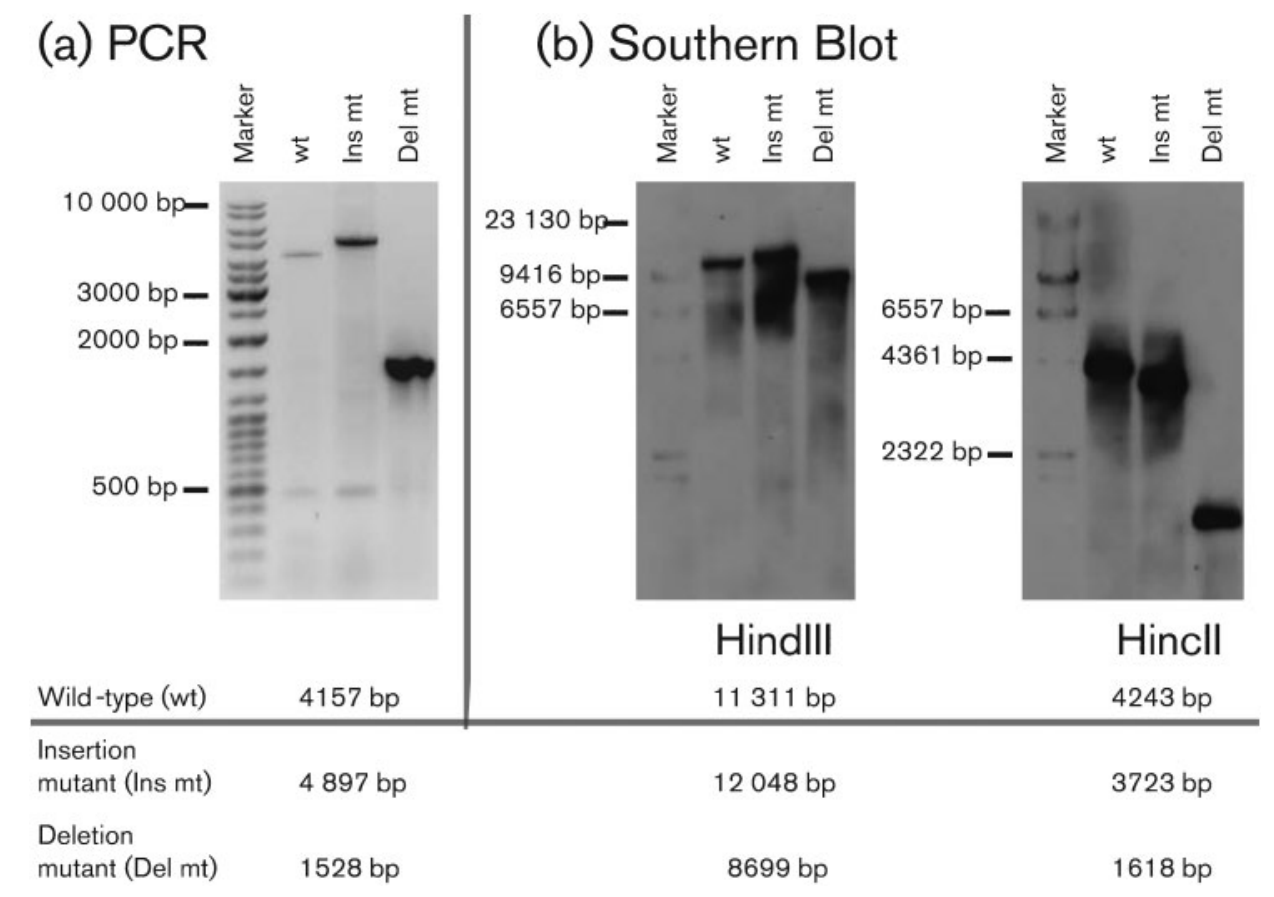

Fig. 1. Confirmation of the segregation of Synechocystis insertion (Ins $\mathrm{mt}$ ) and deletion (Del mt) mutants by PCR amplification using a primer upstream of hoxU and another within $f a b F(a)$ and by Southern blot hybridization (b). Genomic DNA was digested with Hindlll or Hincll and hybridized with a probe covering the $5^{\prime}$ flanking region of hox $Y H$ genes. The expected sizes of the PCR products and restriction fragments are shown below the figure. 


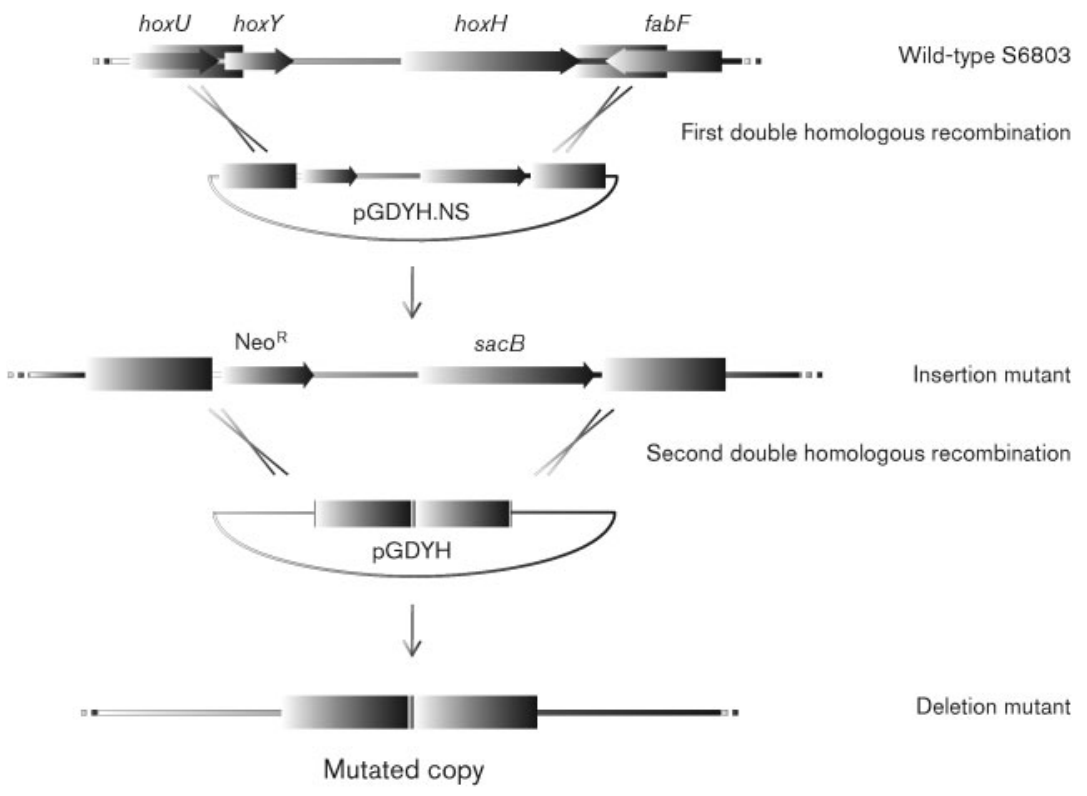

Fig. 2. Schematic representation of the experimental design used to generate the Synechocystis $\triangle$ hoxYH mutant.

In addition, we can obtain the time $\left(t_{\text {imax }}\right)$ at which maximum specific growth is reached and the corresponding optical density recorded $\left(x_{\text {imax }}\right)$.

From the three replicas of any of the experimental samples with a given level of light, nitrate and glucose, it was possible to calculate confidence intervals for the sample growth parameters, corrected using Student's $t$-test. The usual confidence level of $95 \%$ was selected and used to represent mean and error bars in Fig. 3.

Sample collection, protein extraction and iTRAQ labelling. Cells were collected by centrifugation, the supernatant (medium) was removed, the pellets were snap-frozen in liquid nitrogen and preserved at $-80{ }^{\circ} \mathrm{C}$ prior to protein extraction. The protein extraction and quantification was performed as described by Gan et al. (2007). Protein samples $(100 \mu \mathrm{g})$ were precipitated, prepared and digested as described by Chong et al. (2006). iTRAQ 8-plex labelling (ABSciex) was performed as described by Ow et al. (2009).

LC-MS and MS analysis. Two biological Synechocystis wild-type replicates were labelled with the 117 and 118 reagents and two biological $\triangle$ hoxYH mutant replicates were labelled with the 119 and 121 reagents (ABSciex). Peptide pre-fractionation of complex iTRAQlabelled lysate was performed as described by Gan et al. (2007). Peptide detection was performed using LC-MS-MS iTRAQ compatible settings (see Gan et al., 2007). Protein quantification and identification was carried out using Phenyx Software version 2.6 (Genebio). Spectra were searched against the Uniprot database (accessed August 2009), containing 3576 protein sequences of Synechocystis. The false discovery rate (FDR) was calculated using a reverse database generated with Phenyx (Reidegeld et al., 2008), as described by Elias \& Gygi (2007). Both the true and the reversed database were searched in the same run. The FDR was below $5 \%(\mathrm{Ow}$ \& Wright, 2009). Searches were performed in four steps in order to increase proteome coverage (see Supplementary Methods, available with the online version of this paper). Mass tolerances were set to 0.4 Da MS and 0.4 Da MS-MS. The peptide modifications were the same for each search (MMTS, fixed cysteine modification; oxidation, variable; iTRAQ_8plex_K, fixed; iTRAQ_8plex_N, fixed). The peptide lists generated by Phenyx were analysed as described by Ow et al. (2009). This list was used for further analysis as described by Pham et al. (2010) to produce a list of differentially expressed proteins. Protein function and annotations were assigned according to CyanoBase (Nakamura et al., 2000).

Pathway-level analysis of the proteomic data. The network modelling approach 'mixture model on graphs' (MMG) (Noirel et al., 2008; Sanguinetti et al., 2008) was used on the metabolic network of Synechocystis as given by the Kyoto Encyclopedia of Genes and Genomes (KEGG; accessed September 2009). This provides a pathway-level detection of changes based on the proteomics dataset, even when the changes are too small to pass the statistical test used to detect differential expression (for details see Noirel et al., 2009). Briefly, this method classifies the genes' products into three categories: upregulated, downregulated or unregulated. This is based on assumed distribution of the log ratios (Gaussian distribution for unregulated proteins, exponential distribution for differentially regulated proteins) and the topology of the network: if an enzyme is surrounded in the metabolic network by other upregulated enzymes, it will be more likely to be classified as upregulated. The details are described by Sanguinetti et al. (2008).

An improvement with respect to the original implementation has been introduced here: instead of using a single variance parameter $\sigma^{2}$ for the unregulated proteins' Gaussian distribution, a protein-specific variance $\sigma^{2}$ is introduced. It is calculated as

$\sigma^{2}={\sigma_{\mathrm{B}}}^{2}+\left({\sigma_{117}}^{2}+{\sigma_{118}}^{2}+{\sigma_{119}}^{2}+{\sigma_{121}}^{2}\right) / \mathrm{n}$

where the biological variation $\sigma_{\mathrm{B}}{ }^{2}$ is estimated from all eight-plex values; $\sigma_{117}{ }^{2}$ etc. represent the peptide-level, technical variation which is adjusted by the number of MS-MS spectra, $n$. Proteins whose quantifications are more reliable will therefore be more reliably classified.

Sample collection and RNA extraction for transcriptional studies. The sample collection for RNA extraction is depicted in Fig. 4. Briefly, three independent cultures of Synechocystis wild-type and $\Delta$ hoxYH mutant cells were grown under standard conditions (see above) and at the middle of the light phase, they were transferred to the dark and sparged with argon to induce anaerobiosis. Samples were collected 0, 60 and 120 min after anaerobiosis induction $\left(t_{0}, t_{60}\right.$ and $t_{120}$, respectively). In addition, extra cultures were put back in light 


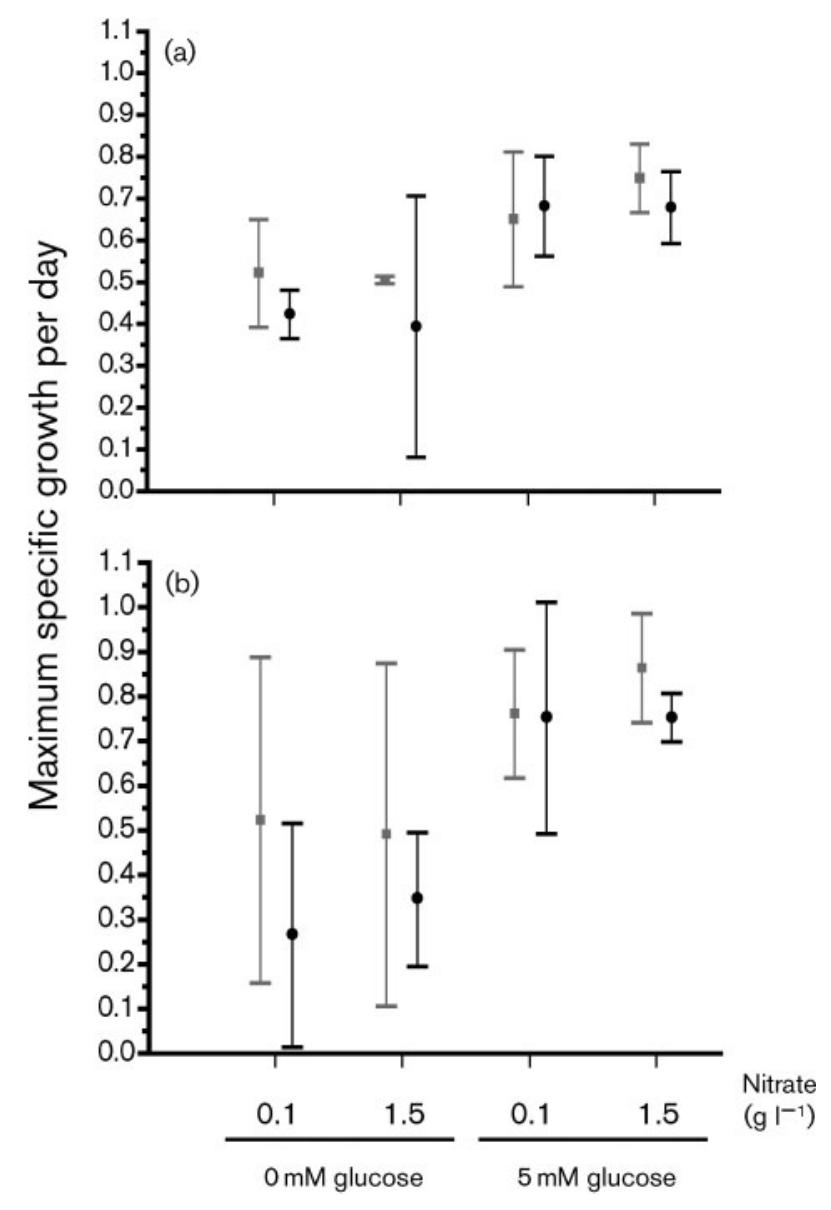

Fig. 3. Mean of the maximum specific growth of Synechocystis wild-type $(\square)$ and $\Delta$ hox $Y H$ mutant $(\bullet)$, under different nitrate, glucose and light regimens: (a) $12 \mathrm{~h}$ light $\left(20 \mu \mathrm{E} \mathrm{m} \mathrm{m}^{-2} \mathrm{~s}^{-1}\right) / 12 \mathrm{~h}$ dark regimen; (b) continuous light $\left(20 \mu \mathrm{E} \mathrm{m} \mathrm{m}^{-2} \mathrm{~s}^{-1}\right)$. Whiskers represent confidence intervals. Mean and confidence intervals limits were calculated and corrected using the Student's $t$ distribution.

$60 \mathrm{~min}$ after anaerobiosis induction, and samples were collected 60 min later $\left[\mathrm{t}_{120(60 \mathrm{~L})}\right]$. To inhibit RNA transcription, rifampicin was added to each sample upon harvesting at a final concentration of $300 \mu \mathrm{g} \mathrm{ml}^{-1}$. Cells were centrifuged $\left(8 \mathrm{~min}\right.$ at $\left.4500 \mathrm{~g}, 4{ }^{\circ} \mathrm{C}\right)$ and washed once with fresh BG11, and the cell pellets were frozen at $-80{ }^{\circ} \mathrm{C}$. RNA was extracted using the TRIZOL Reagent (Invitrogen) according to the method described previously (Leitão et al., 2006). RNA was quantified on a NanoDrop 2000 spectrophotometer (Thermo Scientific) and the quality was checked using the Experion RNA StdSens Analysis kit (Bio-Rad).

Transcription analysis by real time quantitative PCR (RTqPCR). For cDNA synthesis, $1 \mu \mathrm{g}$ total RNA was transcribed with the iScript Select cDNA Synthesis kit (Bio-Rad), using the random primers supplied and following the manufacturer's instructions. The primer pairs used for the gene transcription analysis are listed in Table 1 and Supplementary Table S1 (available with the online version of this paper), and were designed using Beacon Designer 6 software (PREMIER Biosoft International). For each analysis, the 16S rRNA was used for normalization. The real-time PCRs

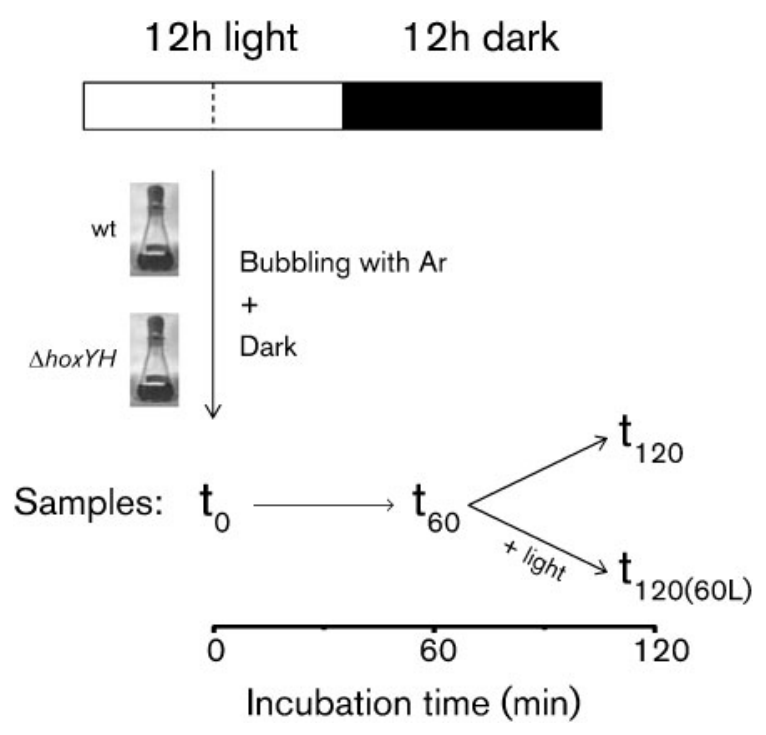

Fig. 4. Schematic representation of the experimental procedure for the collection of the samples for the RNA extraction used for RT-qPCR.

were performed using $0.25 \mu \mathrm{M}$ each primer, $10 \mu \mathrm{l}$ iQ SYBR Green Supermix (Bio-Rad) and $2 \mu \mathrm{l}$ template cDNA, and technical triplicates were performed. The PCR profile was: $3 \mathrm{~min}$ at $95{ }^{\circ} \mathrm{C}$ followed by $40-60$ cycles of $30 \mathrm{~s}$ at $95{ }^{\circ} \mathrm{C}, 30 \mathrm{~s}$ at $51{ }^{\circ} \mathrm{C}$ and $30 \mathrm{~s}$ at $72{ }^{\circ} \mathrm{C}$; exceptionally the annealing temperature for the study of atpC and $p p a$ was $53{ }^{\circ} \mathrm{C}$ and $54{ }^{\circ} \mathrm{C}$ for $p g k$. Standard dilutions of the cDNA were used to check the relative efficiency and quality of primers. Negative controls (no template cDNA) were included in all assays. A melting curve analysis was performed at the end of each PCR program, to exclude the formation of non-specific products. Real time quantitative PCRs (RT-qPCRs) were carried out in the iCycler iQ5 Real-Time PCR Detection System (Bio-Rad). The data obtained were analysed using the Bio-Rad iQ5 Optical System Software v2.1 (Bio-Rad). The two-way ANOVA statistical analysis of the data obtained in the RTqPCR experiment was performed using the software GraphPad Prism v5 (GraphPad Software), comparing Synechocystis $\Delta$ hoxYH mutant with the wild-type, under dark anoxic conditions $\left(t_{0}, t_{60}\right.$ and $\left.t_{120}\right)$ and after cells were transferred back to light $\left[\mathrm{t}_{60}\right.$ and $\left.\mathrm{t}_{120(60 \mathrm{~L})}\right]$.

\section{RESULTS AND DISCUSSION}

\section{Construction and physiological characterization of Synechocystis sp. PCC 6803 AhoxYH deletion mutant}

The genes coding for the two subunits corresponding to the hydrogenase part of the bidirectional hydrogenase (hoxYH) were deleted from the Synechocystis genome in a two-step procedure: a first transformation was performed using the plasmid pGDYH.NS in order to replace hoxYH with a selection cassette conferring kanamycin resistance and sucrose sensitivity, followed by a second transformation, using the plasmid pGDYH, in order to remove the selection cassette. The complete segregation of both mutants was confirmed by resistance/sensitivity to kanamycin/sucrose, 
and by PCR and Southern blot (Fig. 1). The absence of $\mathrm{H}_{2}$ evolution (bidirectional hydrogenase activity) by the $\Delta$ hoxYH mutant was confirmed by gas chromatography (data not shown). To elucidate the possible effects of this mutation on the fitness of Synechocystis, the growth of both the wild-type and the $\Delta h o x Y H$ mutant was compared under several physiological conditions (see Methods). In Fig. 3(a) the sample mean of maximum specific growth, $\mu_{\max }$, at different levels of nitrate and glucose, under $12 \mathrm{~h}$ light $\left(20 \mu \mathrm{E} \mathrm{m}^{-2} \mathrm{~s}^{-1}\right) / 12 \mathrm{~h}$ dark cycles for Synechocystis wild-type and $\Delta$ hox $Y H$ mutant are shown. As can be observed, in the presence of $1.5 \mathrm{~g}$ nitrate $\mathrm{l}^{-1}$ and with glucose, the wild-type $\mu_{\max }$ increases significantly compared with the same conditions in the absence of glucose. In Fig. 3(b), with continuous $20 \mu \mathrm{E} \mathrm{m}^{-2} \mathrm{~s}^{-1}$ irradiance, glucose increases maximum specific growth, while nitrate decreases the variability of the mutant. In conclusion, these analyses show no significant difference in terms of specific growth for Synechocystis wild-type and $\Delta$ hoxYH mutant under the different levels of nitrate, glucose and irradiance used. These results are in agreement with what was previously reported for a disruption mutant (with a kanamycin resistance cassette within hoxH) growing in continuous light $(100 \mu \mathrm{E}$ $\mathrm{m}^{-2} \mathrm{~s}^{-1}$ ) and bubbled with air (Appel et al., 2000). However, differences in growth have been detected when cultures were bubbled with $\mathrm{CO}_{2}$-enriched air $[2 \%(\mathrm{v} / \mathrm{v})$ $\mathrm{CO}_{2}$ ], suggesting that $\Delta$ hoxH cells need more time than the wild-type to reach the maximal growth rate (Appel et al., 2000).

The role of the bidirectional hydrogenase in cyanobacterial metabolism is not fully understood (Bothe et al., 2010a; Carrieri et al., 2011; Tamagnini et al., 2007). However, it was hypothesized by Ludwig et al. (2006) that the ancestor of cyanobacteria would have vertically transmitted the two hydrogenases genes (hox-bidirectional hydrogenase, hupuptake hydrogenase), and that none, one or both enzymes were subsequently lost through evolution. Thus, the current distribution would be the result of cyanobacterial adaptation to various ecological niches. About $50 \%$ of the
$\mathrm{N}_{2}$-fixing strains do not possess the bidirectional hydrogenase (Ludwig et al., 2006; Schütz et al., 2004; Tamagnini et al., 1997, 2000), and although most of the non- $\mathrm{N}_{2}$-fixing strains contain it, this enzyme does not seem to be essential for cell survival (Appel et al., 2000; Masukawa et al., 2002). Accordingly, our results suggest that, under the conditions tested, the bidirectional hydrogenase has no significant effect on the fitness of Synechocystis. Altogether, and taking also into account the results obtained by Appel et al. (2000), the absence of this enzyme seems to have only a marginal effect.

\section{Comparison of the proteomes of wild-type Synechocystis and of the $\Delta$ hoxYH mutant}

The proteomes of Synechocystis wild-type and of the $\Delta$ hoxYH mutant were analysed using the iTRAQ methodology, under conditions in which the hydrogenase activity is favoured - dark anoxic conditions - and the effect of the mutation should be easily observed (Cournac et al., 2002, 2004). In total, 210 proteins were identified using Phenyx v2.6, of which there were 145 with two or more MS/MS spectra; false positive discovery rate was estimated to be $1.7 \%$. None of the bidirectional hydrogenase subunits was detected, probably due to their low abundance in the cells. To date, only Gan et al. (2005) have been able to identify a bidirectional hydrogenase subunit in proteomics studies. Out of the 210 proteins identified, 192 proteins were quantified, of which there were 131 with two or more MS-MS spectra. The methodology for quantification was described by $\mathrm{Ow}$ et al. (2009). The peptide matches and the protein identifications and quantifications are included in Supplementary Table S2, as recommended by Noirel et al. (2011). The quantified proteins were further analysed to determine which ones had their levels significantly altered by the $\Delta$ hox $Y H$ mutation, according to the method used by Pham et al. (2010). According to this analysis, 17 proteins were differentially expressed, with a $95 \%$ confidence interval, with five being less abundant in the mutant (Fig. 5 and Table 2). Sixteen of these proteins

Functional categories

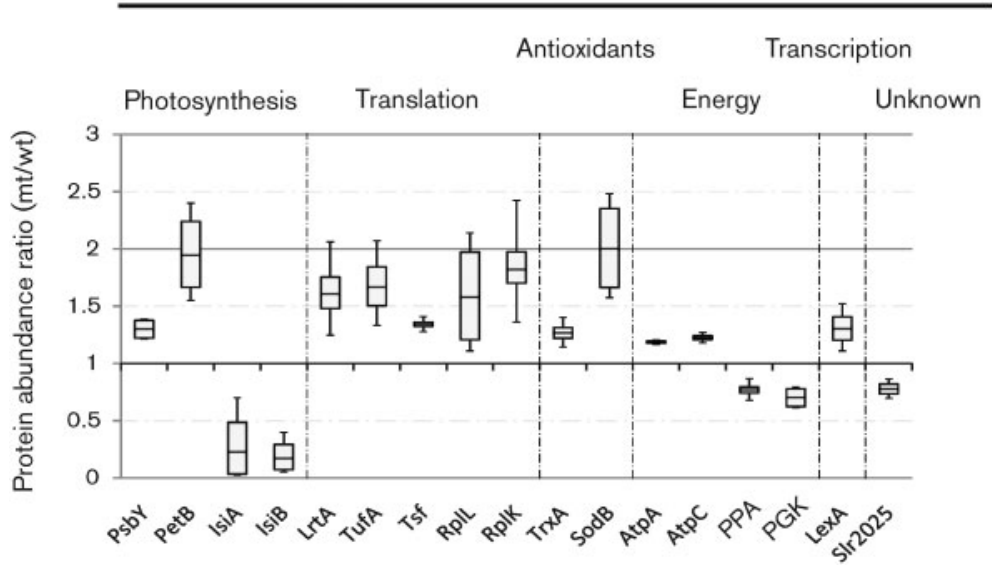

Fig. 5. Box-and-whisker plot of the abundance ratio between proteins showing significant differential fold changes in Synechocystis $\Delta h o x Y H$ mutant and wild-type. The proteins are grouped according to their functional categories. 
Table 2. List of proteins exhibiting significant differences in their abundance in Synechocystis $\Delta$ hox $Y H$ mutant compared with the wild-type strain, after induction of dark anoxic conditions

Functional categories: PR, photosynthesis and respiration; Tl, translation; AD, antioxidant defences; EM, energy metabolism; Tr, transcription; U, unknown.

\begin{tabular}{|c|c|c|c|c|}
\hline ID & Gene $^{*}$ & Protein & Putative function/characteristics of the encoded protein ${ }^{\star}$ & Category \\
\hline sllo248 & $i s i B$ & IsiB & Flavodoxin & $\mathrm{PR}$ \\
\hline sll1099 & tufA & TufA & Elongation factor $\mathrm{Tu}$ & $\mathrm{Tl}$ \\
\hline sll1261 & $t s f$ & Tsf & Elongation factor Ts & $\mathrm{Tl}$ \\
\hline sll1326 & $\operatorname{atp} A$ & AtpA & ATP synthase alpha chain & EM \\
\hline sll1626 & $\operatorname{lex} A$ & LexA & Transcription factor & $\operatorname{Tr}$ \\
\hline sll1743 & rpl11 & RplK & 50 S ribosomal protein L11 & $\mathrm{Tl}$ \\
\hline sll1746 & rpl12 & RplL & 50 S ribosomal protein L12 & $\mathrm{Tl}$ \\
\hline slr0342 & petB & PetB & Cytochrome $b_{6}$ & PR \\
\hline slr0394 & $p g k$ & PGK & Phosphoglycerate kinase & EM \\
\hline slr0623 & $\operatorname{tr} x A$ & $\operatorname{TrxA}$ & Thioredoxin & $\mathrm{AD}$ \\
\hline
\end{tabular}

${ }^{\star}$ According to CyanoBase annotation.

fit into five functional categories: photosynthesis and respiration (IsiA, IsiB, PetB and PsbY), translation (LrtA, RplL, RplK, Tsf and TufA), antioxidant defences (SodB and $\operatorname{TrxA}$ ), energy metabolism (AtpA, AtpC, PGK and PPA) and transcription (LexA). Additionally, a protein of unknown function was identified (Slr2025). The differential expression of each one of these proteins will be discussed in light of the putative roles of the bidirectional hydrogenase.

The association of the bidirectional hydrogenase activity with the photosynthetic and respiratory processes has been extensively discussed previously (e.g. Appel \& Schulz, 1996, 1998; Appel et al., 1999, 2000; Ludwig et al., 2006; Schmitz \& Bothe, 1996). In both cases, the bidirectional hydrogenase would serve as an important element for a proper redox balance of the electron-transport chains in transition states (Appel \& Schulz, 1998). Our results revealed the higher abundance of a photosystem II (PSII) protein (PsbY) and of PetB in the $\Delta$ hoxYH mutant, indicating that both photosynthetic and respiratory machineries are being affected by the loss of hydrogenase activity. Moreover, the photosynthesis-associated proteins IsiA and IsiB, which are expressed under iron-deficiency conditions, were less abundant in the $\Delta$ hoxYH mutant, suggesting a higher bioavailability of this metal in the mutant. Since the cyanobacterial hydrogenases are metalloproteins possessing iron-sulfur clusters and nickel-iron active sites, it is likely that the absence of this enzyme could contribute to higher iron content in the mutant cells. It has been suggested that, in Synechocystis, the isiAB operon is under the control of the ferric uptake regulator (Fur) (Kunert et al., 2003; Vinnemeier et al., 1998). The importance of Fur is not limited to its participation as a modulator in all the irondependent-regulation genes; it has been shown that Fur is involved in the oxidative stress response (Nunoshiba et al., 1999) and in overcoming acidic stress situations (Hall \& Foster, 1996). Therefore, the lower abundance of IsiA and IsiB in the $\Delta$ hox $Y H$ mutant could be related to a stress condition that the cells have to cope with.

The higher abundance of the five proteins involved in translation in the $\Delta h o x Y H$ mutant indicates that protein synthesis is altered. Two of these proteins are structural components of the ribosome (RplK and RplL) and two others are involved in the process of translation itself (TufA and Tsf), indicating a reinforcement of the translational machinery in the mutant. Additionally, LrtA belongs to the $\sigma^{54}$ modulation protein/ribosomal protein S30EA family and is also more abundant in the $\Delta$ hoxYH mutant. Although no clear function has been attributed to this protein, its homologue in E. coli - the ribosome binding protein Y (YfiA) - putatively works as a stress-response protein that binds the ribosomal subunit interface and arrests translation (Agafonov et al., 2001; Vila-Sanjurjo et al., 2004). The increased levels of LrtA in the mutant suggest a tighter control of translation, as a response to the stress condition caused by the absence of the bidirectional hydrogenase. Moreover, according to CyanoBase, this protein is assigned to the functional category of 'adaptations and atypical conditions'. Furthermore, a large-scale analysis of Synechocystis protein-protein interaction (Sato 
et al., 2007) reported that LrtA interacts with a hypothetical protein encoded by sll1773, which is a Pirin-like protein induced under stress conditions (Hihara et al., 2004).

Interestingly, even after oxygen has been removed from the medium, Synechocystis $\Delta$ hoxYH mutant cells still display increased levels of the enzymes SodB and TrxA, which act as antioxidant defences. SodB, the iron superoxide dismutase $(\mathrm{Fe}-\mathrm{SOD})$, catalyses the elimination of superoxide radicals $\left(\mathrm{O}_{2}^{--}\right)$. The higher levels of this protein may indicate a more reductive intracellular environment, leading to an increased concentration of toxic oxygen reduction products, and therefore, the necessity for higher levels of antioxidant defences. Furthermore, Nefedova et al. (2003) reported that mutants lacking SodB are non-viable under standard photoautotrophic conditions, emphasizing the importance of the Fe-SOD for providing resistance of Synechocystis cells to oxidative stress. Thioredoxins constitute a large family of redox-active enzymes, capable of reducing protein disulphides, and participate in a variety of processes, such as enzyme modulation, donation of reducing equivalents and signal transduction. Lindahl \& Florencio (2003) have identified several proteins in Synechocystis likely to be thioredoxin (TrxA) substrates, mainly enzymes participating in anabolic processes. Among these is the elongation factor EF-Tu (TufA), which has been reported to interact with chloroplast thioredoxins (Motohashi et al., 2001). Both TrxA and TufA levels are increased in the $\Delta$ hoxYH mutant compared with the wild-type. It has been suggested that TrxA is regulated by the photosynthetic electron transport (Navarro et al., 2000; Pérez-Pérez et al., 2009); therefore, the differential expression of TrxA protein may be due to a higher redox imbalance in the mutant. Again, significant changes in proteins related to defence mechanisms suggest the mutant is coping with a stress generated by the lack of the bidirectional hydrogenase, and this stress is likely to be related to the redox state of the cell.

Regarding the energy-metabolism-related proteins, two subunits of the ATP synthase (AtpA and AtpC) were more abundant in the $\Delta$ hoxYH mutant, while the phosphoglycerate kinase (PGK) and soluble inorganic pyrophosphatase (PPA) were less abundant. The ATP synthase is a ubiquitous membrane enzyme complex that functions to couple ATP synthesis to proton translocation across a membrane and, in cyanobacteria, this complex is present in both thylakoid and plasma membranes (Sherman et al., 1994). The higher abundance of the two ATP synthase subunits suggests a higher requirement for this enzyme, under the conditions tested. Since the mutant lacks an active bidirectional hydrogenase, which is responsible for the reduction of protons to molecular hydrogen under anoxic conditions, one can hypothesize that the higher abundance of the ATP synthase is a cellular mechanism to cope with the excess of $\mathrm{H}^{+}$in order to maintain intracellular $\mathrm{pH}$ homeostasis. This mechanism has already been described for cell adaptations to changes in $\mathrm{pH}$ (Padan et al., 2005; Summerfield \& Sherman, 2008). PGK is the enzyme catalysing the reversible phosphorylation of 3-phosphoglycerate to 1,3-diphosphoglycerate. It is involved in the Calvin cycle, in glycolysis and in the glycolytic degradation of glycogen (fermentation). In the filamentous cyanobacterium Arthrospira (Spirulina) maxima, $\mathrm{H}_{2}$ evolution represents a major pathway for energy (ATP) production during fermentation by regenerating the $\mathrm{NAD}^{+}$essential for the glycolytic degradation of glycogen and the catabolism of other substrates (Ananyev et al., 2008). The lower abundance of PGK in the mutant under dark anoxic conditions can, therefore, be related to a decrease in the glycogen catabolism, due to a lower availability of $\mathrm{NAD}^{+}$. PPA is an essential and ubiquitous metal-dependent enzyme that is thought to be involved in the removal of inorganic pyrophosphate (PPi), which is a by-product of many vital anabolic reactions (Kornberg, 1962). It has been shown that PPA function is essential for cell viability and that this protein is more abundant in Synechocystis cells subjected to phosphate deprivation (Gómez-García et al., 2003). Accordingly, the lower abundance of PPA in the mutant suggests a higher availability of phosphate within the cells.

The transcription factor LexA is encoded in almost every bacterial group with a wide range of evolutionary distances and plays an important role in the SOS response in E. coli (Fernández de Henestrosa et al., 2000; Little \& Mount, 1982). Still, its precise functions in each group/species are largely unknown. It has been shown that in several cyanobacteria this protein interacts with the promoter region of the bidirectional hydrogenase (Antal et al., 2006; Gutekunst et al., 2005; Oliveira \& Lindblad, 2005, 2009; Sjöholm et al., 2007) and it has been suggested that LexA is a mediator of the redox state in Synechocystis cells (Antal et al., 2006; Patterson-Fortin et al., 2006). Interestingly, the LexA regulator was more abundant in the $\Delta$ hox $Y H$ mutant. Since it was proposed that LexA acts as a transcriptional activator of the hox genes in Synechocystis (Gutekunst et al., 2005), the higher abundance of LexA could be a cellular response to the lack of a functional bidirectional hydrogenase. It can be postulated that a feedback loop leads to an increased quantity of activator that in the wild-type would promote the transcription of the hox genes. Moreover, a predictive analysis of LexA binding sites on 26 sequenced cyanobacterial genomes (Li et al., 2010) showed that this protein could regulate the expression of some of the genes reported in this study: $p s b Y, p p a, p g k$, petB, isiB, tsf, trx $A$, rpl12, rpl11 and lexA itself.

According to a similarity BLAST analysis (Johnson et al., 2008), the protein Slr2025 belongs to the DUF1821 protein family, which comprises uncharacterized proteins principally found in cyanobacteria with subunit and dimer structures similar to the 'Type III secretory system chaperone' from proteobacteria. In a large-scale protein-protein interaction analysis in Synechocystis (Sato et al., 2007) using the yeast two-hybrid (YTH) system it was revealed that Slr2025 interacts with four other proteins: Slr2037 (unknown protein), Slr1444 (hypothetical protein), Sll1875 (HO2, haem oxygenase) and notably Sll1226 
(HoxH, hydrogenase large subunit of the bidirectional hydrogenase).

Overall, the iTRAQ results indicate that, under dark anoxic conditions, Synechocystis cells lacking a functional bidirectional hydrogenase have to cope with a more stressful intracellular environment. Nonetheless, the cellular responses triggered seem to be sufficient to avoid a major interference in its metabolism as a whole. These conclusions are consistent with our growth experiments that showed no significant differences between the wild-type and $\Delta h o x Y H$ mutant, under the conditions tested. Moreover, the proteins with altered levels are mainly related to the redox and energy state of the cells, corroborating the previously attributed role of the bidirectional hydrogenase in avoiding an overload of low potential electrons in the electron transport chains (Appel \& Schulz, 1998; Appel et al., 2000; Carrieri et al., 2011; Cournac et al., 2002, 2004).

\section{Pathway analysis}

The analysis based on 'mixture model on graphs' (MMG) provided some insight into the biological pathways that may undergo subtler, yet wider regulation patterns (see Supplementary Fig. S1 and Supplementary Table S2, available with the online version of this paper). This reveals and predicts changes in the central metabolism that had not been detected using the traditional protein-to-protein analysis of the previous section. Although individual protein quantifications are questionable, overall the evidence at the pathway level seems to point at a general downregulation of the pentose phosphate pathway (PPP), of glycolysis/ gluconeogenesis and of the glyceraldehyde-3-phosphate-topyruvate route (see Fig. 6). This is of particular interest if we consider the putative involvement of the bidirectional hydrogenase in fermentation. It has been proposed that during fermentation in Cyanothece sp. PCC 7822, protons may serve as terminal electron acceptors, being reduced to molecular hydrogen in a hydrogenase-catalysed reaction (van der Oost et al., 1989). In addition, two possible fermentative pathways are: (i) the heterofermentative lactate fermentation, via the pentose phosphate pathway; and (ii) the CoA-dependent decarboxylation of pyruvate, via glycolysis (Stal \& Moezelaar, 1997; van der Oost et al., 1989). In a recent study, McNeely et al. (2010) reported the successful improvement of hydrogen production in Synechococcus sp. PCC 7002, by redirecting the reductant flux, through metabolic engineering. In their study, the gene encoding Dlactate dehydrogenase (ldhA), responsible for the formation of the main fermentation product (lactate) was inactivated, resulting in the increase of other metabolic by-products, namely hydrogen. Interestingly, the $l d h A$ mutant did not exhibit significant differences in terms of photoautotrophic growth in aerobic respiration either. In our study, in the absence of an active hydrogenase, capable of producing hydrogen to remove the excess reducing equivalents produced during the fermentative degradation of carbohydrates, it is reasonable to expect (i) a downregulation of the pathways originating this reducing power (namely glycolysis and PPP) and/or (ii) an increase in other metabolic byproducts. This has to be further investigated, through experiments targeting the fermentative metabolism of the wild-type and the $\Delta$ hoxYH mutant.

\section{Transcription analysis of genes encoding proteins with different abundance in Synechocystis wild- type and $\Delta h o x Y H$ mutant}

To assess if the changes observed at the protein levels were due to transcriptional regulation, RT-qPCR analyses were carried out. This experiment covers all gene clusters encoding the proteins showing different relative levels reported above, with the exception of isiAB and tsf, for which the PCR conditions could not be optimized (secondary amplification products were always detected in the melting curve analysis). For this experiment, three biological and three technical replicates were used (see Methods for further details). Fig. 7 shows the transcriptional analysis of the genes encoding proteins representative of each functional category (full analysis is shown in Supplementary Fig. S2, available with the online version of this paper; graphics were constructed based on one biological replicate representative of the biological variability observed). In all cases, a two-way ANOVA analysis was performed (Table 3), revealing significant differences between the wildtype and the $\Delta h o x Y H$ mutant in the transcription of $p s b Y$, $p e t B, s l r 2025, p p a, p g k$ and lexA. The transcription patterns of the genes $p p a, p g k$, lexA and slr2025 seem to be in agreement with the differences found in the iTRAQ experiment, while for the other two genes ( $p s b Y$ and $p e t B$ ), the changes observed in protein abundance do not seem to be directly related to their transcriptional regulation and, most likely, the regulation is exerted at post-transcriptional and/or protein synthesis/degradation levels.

Additionally, this experiment revealed significant variations in the transcript levels of all genes under the physiological conditions tested (dark-anaerobiosis/light-aerobiosis). Overall, the genes exhibited one of the following transcription patterns: (i) induction under dark anoxic conditions and repression by light ( $\operatorname{sod} B$ ); (ii) repression under dark anoxic conditions and induction by light ( $a t p C, p s b Y$ and $\operatorname{tr} x A)$; (iii) induction under dark anoxic conditions and unaffected by light (lexA); (iv) repression under dark anoxic conditions and unaffected by light ( $p e t B, p g k, p p a, s l r 2025$ and tufA); and (v) transient induction under dark anoxic conditions and unaffected by light ( $l r t A$ and $r p l K$ ). The transcription patterns of the genes grouped in (i), (ii) and (iii), which presented greater transcript levels variations, and pet $B$ that presented an inverse correlation with the proteomics analysis, will be discussed.

Interestingly, sodB transcript levels increased after anaerobiosis induction and decreased when cells were transferred back to the light. These results are unexpected, since it has been previously shown that, in Synechocystis, sodB expression is light-dependent, being downregulated in the 


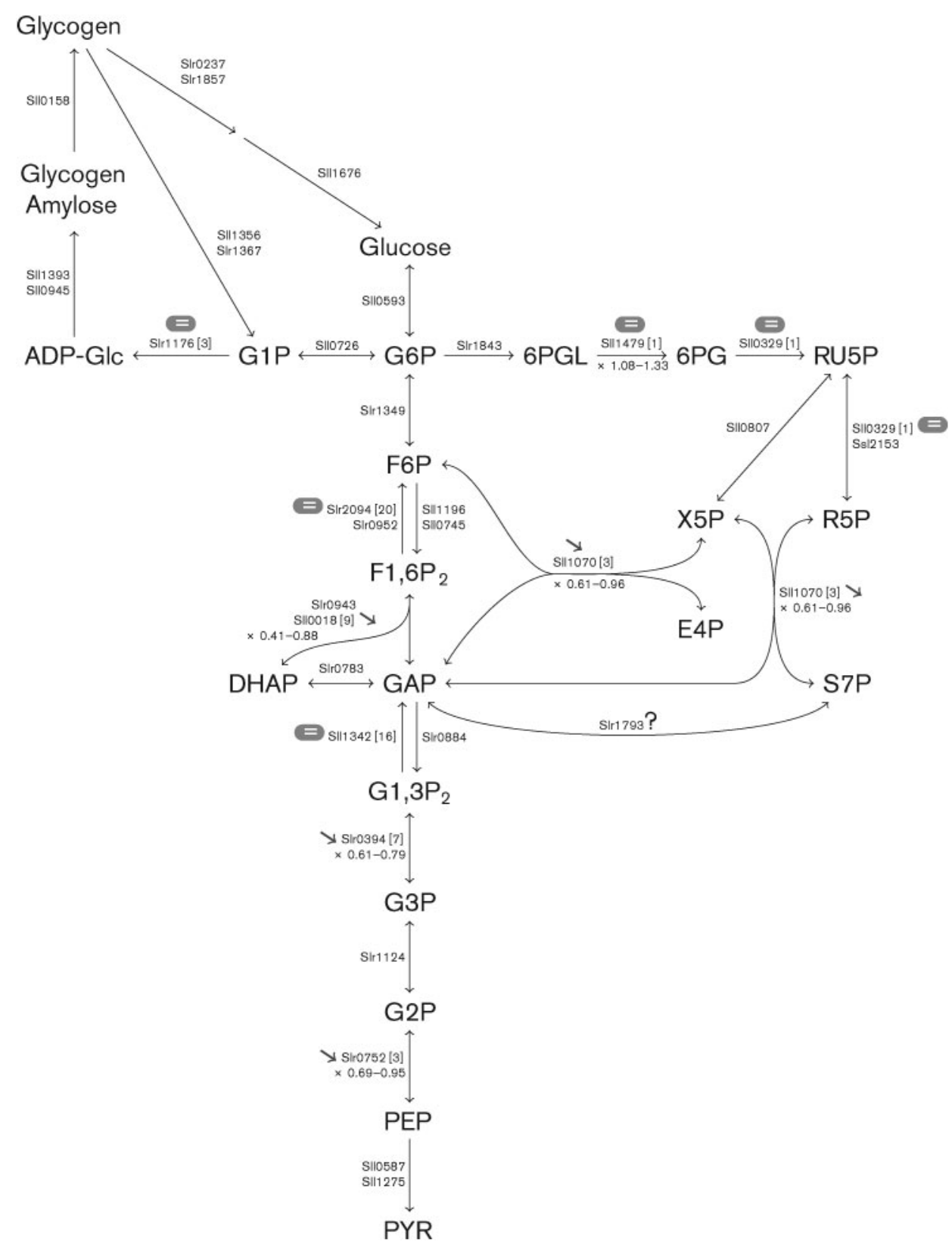

Fig. 6. Protein changes in the glycolysis/gluconeogenesis, the PPP pathway and glycogen metabolism in Synechocystis $\Delta$ hox $Y H$ mutant according to the MMG analysis. The arrows indicate underexpression of enzymes in the mutant and the equals signs indicate expression levels that are not significantly different. The number of MS/MS spectra used for quantification is indicated in brackets (adapted from Osanai et al., 2005). Abbreviations: G1P, glucose-1-phosphate; G6P, glucose 6phosphate; 6PGL, 6-phosphogluconolactone; 6PG, 6-phosphogluconate; F6P, fructose-6-phosphate; F1,6P , fructose 1,6bisphosphate; GAP, glyceraldehyde 3-phosphate; DHAP, dihydroxyacetone phosphate; G1,3P $2,1,3$-bisphosphoglycerate; G3P, 3-phosphoglycerate; G2P, 2-phosphoglycerate; PEP, phosphoenolpyruvate; PYR, pyruvate; RU5P, ribulose-5phosphate; R5P, ribose 5-phosphate; S7P, sedoheptulose 7-phosphate; X5P, xylulose 5-phosphate; E4P, erythrose 4phosphate.

darkness (Kim \& Suh, 2005; Ushimaru et al., 2002). Still, an increase in the transcript levels of $\operatorname{sodB}$ induced by anaerobiosis has already been described for other organisms, although SodB is known to act as an antioxidant defence (Dubrac \& Touati, 2000; Kanematsu \& Sato, 2008).
The increase in $\operatorname{sod} B$ transcript levels was attributed to the Fur regulator, which may play an important role in the oxidative stress response, as referred to above. This may be a mechanism for the cell to prepare and protect itself from an eventual $\mathrm{O}_{2}$ burst and the concomitant production of 
Photosynthesis

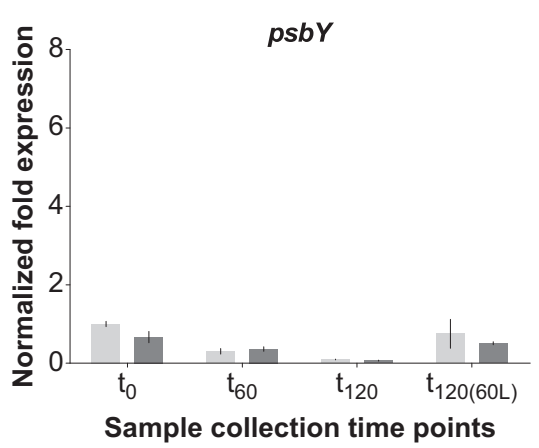

Energy

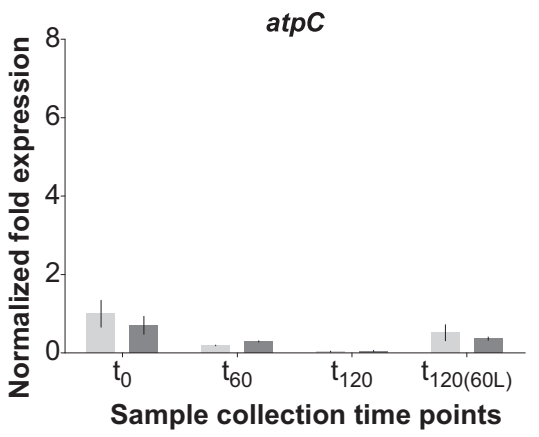

Translation

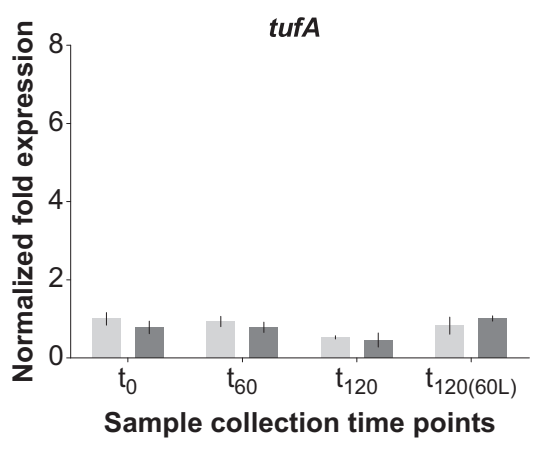

Transcription

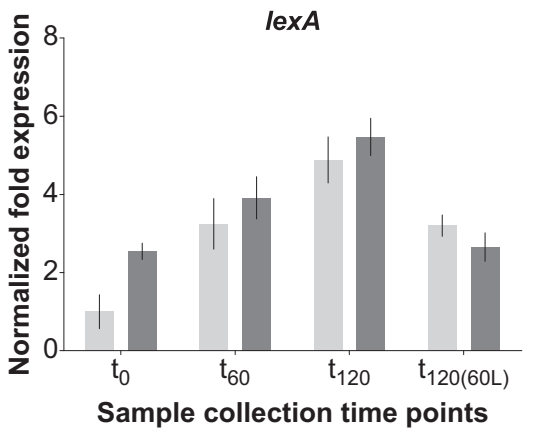

Antioxidants

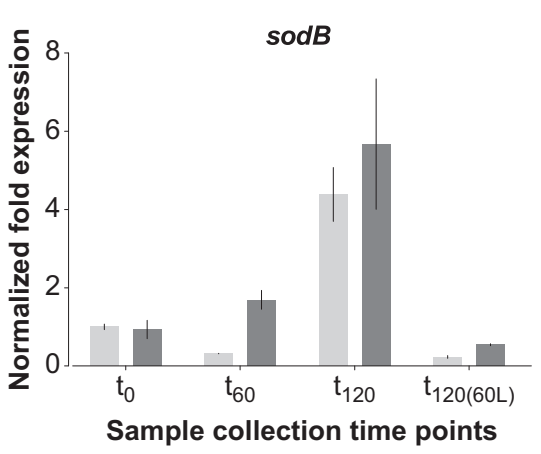

Unknown

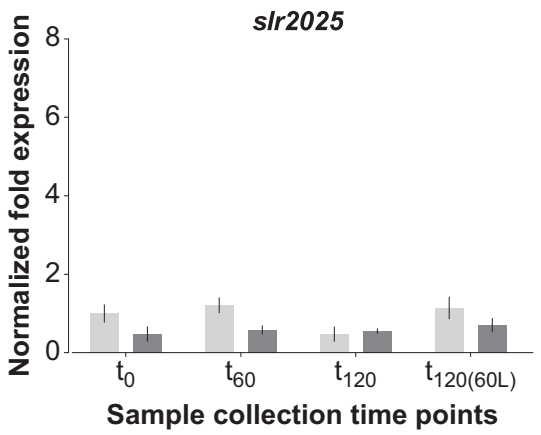

Fig. 7. Transcription profiles of selected genes encoding proteins (one of each functional category, see Fig. 5) showing significant differential fold changes in Synechocystis wild-type (light grey) and $\Delta$ hox $Y H$ mutant (dark grey) and evaluated by RTqPCR. The mean normalized expression was calculated relative to the transcription of the 16S rRNA gene and the reaction internal normalization was performed using the sample $t_{0}$ from Synechocystis wild-type. Error bars represent SD.

Table 3. Statistical significance of the data obtained in the RTqPCR analysis, comparing Synechocystis $\Delta$ hoxYH mutant (mt) with the wild-type (wt) under dark anoxic conditions (Dark) and after transferring cells back to light (Light)

\begin{tabular}{|c|c|c|}
\hline \multirow[t]{2}{*}{ Gene } & \multicolumn{2}{|c|}{$P$-values $\mathrm{mt} / \mathrm{wt}$} \\
\hline & Dark $^{*}$ & Light $\dagger$ \\
\hline$p s b Y$ & $<0.05 /<0.001$ & $\mathrm{NS} /<0.05$ \\
\hline petB & $<0.05 /<0.01$ & NS/NS \\
\hline $\operatorname{lrt} A$ & $\mathrm{NS} /<0.01$ & NS/NS \\
\hline tufA & $\mathrm{NS} /<0.01$ & NS/NS \\
\hline rplK & $\mathrm{NS} /<0.001$ & NS/NS \\
\hline $\operatorname{trx} A$ & $\mathrm{NS} /<0.05$ & $\mathrm{NS} /<0.01$ \\
\hline $\operatorname{sod} B$ & $\mathrm{NS} /<0.001$ & $<0.001 /<0.01$ \\
\hline $\operatorname{atp} C$ & $\mathrm{NS} /<0.01$ & $\mathrm{NS} /<0.05$ \\
\hline$p p a$ & $<0.01 /<0.001$ & NS/NS \\
\hline$p g k$ & $<0.05 /<0.001$ & NS/NS \\
\hline $\operatorname{lex} A$ & $<0.05 /<0.001$ & NS/NS \\
\hline slr2025 & $<0.01 /<0.05$ & $<0.01 / \mathrm{NS}$ \\
\hline
\end{tabular}

${ }^{*}$ Two-way ANOVA analysis of $t_{0}, t_{60}$ and $t_{120}$.

$\dagger$ Two-way ANOVA analysis of $t_{60}$ and $t_{120(60 \mathrm{~L})}$. reactive oxygen species. However, SodB activity did not present major differences before and after light transition, as it was observed in both gel and spectrophotometric superoxide dismutase activity assays (data not shown).

Cyanobacteria switch immediately from photoautotrophy to fermentation when exposed to dark anoxic conditions and, under these conditions, it is expected that the ATP synthase transcription is downregulated. It is generally assumed that the energy yield of fermentation is minimal, thus sustaining only survival (Stal \& Moezelaar, 1997). This implies that biosynthetic processes are switched off during anaerobic dark metabolism in order to decrease energy demand. When the cells are transferred back to light, photosynthesis is reactivated and the requirement for ATP synthase may induce the transcription of the genes coding for its subunits. Moreover, the gene atpC encodes the gamma subunit of the ATP synthase, and AtpC is believed to be involved in the regulation of the ATPase activity and the flow of protons through the membrane-embedded domain of the enzyme ( $\mathrm{CF}_{0}$ complex) (Krenn et al., 1997). Similarly, when cells are transferred into dark conditions, there is a decrease in the transcription of $p s b Y$, which encodes a core component of PSII (Kawakami et al., 2007). 
This is probably due to the cessation of the photosynthesis and downregulation of the transcription of components of the photosystems. A small increase in $p s b Y$ transcript levels can be observed when cells were exposed back to light. In accord with what has been previously described by Navarro et al. (2000) and by Pérez-Pérez et al. (2009), trxA transcription slightly decreases in the dark and increases when cells are transferred to light, exhibiting photosynthetic dependence.

LexA seems to have a broad effect on gene regulation in Synechocystis, and although its precise function is unknown, LexA does not seem to be a regulator of the SOS response in this organism, as has been proposed for other cyanobacteria (Li et al., 2010). Several studies reported that lexA transcription patterns do not always follow the same trend as those of hox genes (Oliveira \& Lindblad, 2008; Zhang et al., 2008), indicating that additional factors may be involved in the regulation of the transcription of the bidirectional hydrogenase genes of Synechocystis (Oliveira \& Lindblad, 2008, 2009). However, our results are in agreement with previous studies that reported an increase in lexA transcript levels under microaerobic conditions (Kiss et al., 2009; Summerfield et al., 2011). In fact, in our study, after induction of dark anoxic conditions, an increase in the transcription of lexA can be observed (see Fig. 7). The fact that the transcription of both lexA and hox genes increases under anaerobiosis (Oliveira \& Lindblad, 2008) and that LexA interacts with the promoter region of the hox genes (Antal et al., 2006; Gutekunst et al., 2005; Oliveira \& Lindblad, 2005, 2009; Sjöholm et al., 2007), suggests that LexA activates the transcription of the hox genes particularly under dark anoxic conditions.

The pet $B$ gene encodes the cytochrome $b_{6}$ subunit of the cytochrome $b_{6} f$ complex that mediates electron transfer between PSII and PSI, cyclic electron flow around PSI and state transitions (Cramer et al., 1994; Kruip et al., 1994; Stroebel et al., 2003). As has been previously reported for Synechococcus sp. PCC 7002 (Brand et al., 1992), petB transcripts decrease when cells are placed in dark conditions. Overall, the transcript levels of petB are lower in the $\Delta$ hoxYH mutant, in contrast with the results obtained at the protein level (which was approximately twofold higher in the mutant), again indicating post-transcriptional regulation. Our results on the transcription of both $p s b Y$ and petB are in disagreement with a study performed using another hydrogenase mutant $(\Delta h o x H)$, where the amounts of the two transcripts were slightly higher than in the wild-type (Appel et al., 2000). However, in that work, Northern blot hybridizations were performed using RNA isolated from 7day-old cultures, grown under light and bubbled with air; therefore a direct comparison with the present study is not possible. Nonetheless, both studies concur that the hydrogenase has an effect on the regulation of the petB gene.

Interestingly, a recent study on Synechocystis gene expression under low oxygen conditions, revealed changes in a number of genes coding for proteins putatively involved in assembling or stabilizing PSII, and an upregulation of the hox operon and lexA (Summerfield et al., 2011). These responses, mostly focused on PSII and overall redox control, suggest an involvement of the bidirectional hydrogenase in the cell homeostasis under specific conditions or transition states.

A peculiar observation, regarding the genes coding for the proteins showing differential abundance (iTRAQ analysis), is that most of them are located in the same half of the Synechocystis chromosome, surrounding the hox cluster (see Supplementary Fig. S3, available with the online version of this paper), with a binomial test giving a $P$-value $<0.013$. However, the biological relevance (if any) of this occurrence needs to be further investigated.

In addition, the transcription of genes encoding proteins related to stress response and iron levels was studied: two ferric uptake regulation proteins - Fur (encoded by sll0567 and sll1937) and the Fur-like peroxide-responsive repressor PerR (slr1738) (Kobayashi et al., 2004), the putative glutamate-cysteine ligase GshA, which is the enzyme responsible for the first step in the glutathione biosynthesis pathway (slr0990), a small heat-shock protein, HspA, that stabilizes the thylakoid membrane proteins under oxidative stress (sll1514) (Sakthivel et al., 2009) and the ferritin-type storage complex MrgA (slr1894), suggested to play a role in the coordination of iron homeostasis and oxidative stress response in Synechocystis (Shcolnick et al., 2009). The transcription of $m r g A$ is suggested to be under the control of the PerR regulator and, therefore, induced under oxidative stress ( $\mathrm{Li}$ et al., 2004). Overall, the RT-qPCR results showed no significant differences between the wild-type and the $\Delta$ hoxYH mutant, with the exception of the Fur regulator genes. Significantly $(P<0.05)$ lower levels of sll0567 transcript (in the dark) and a transient decrease in sll1937 transcript levels (60 min after dark anoxic condition induction) could be observed in the mutant (see Supplementary Fig. S4, available with the online version of this paper). Since sll0567 and sll1937 encode transcription factors involved in iron homeostasis, these results suggest differences in iron pools/ availability in the wild-type and the $\Delta h o x Y H$ mutant.

\section{Conclusions}

In conclusion, a Synechocystis mutant lacking an active bidirectional hydrogenase was produced by deleting the two genes - hoxY and hoxH - encoding the hydrogenase part of this enzyme. Physiological studies were performed by growing the wild-type strain and the $\Delta$ hoxYH mutant under different physiological conditions and assessing and comparing their growth behaviour. From this analysis, no significant differences were observed, and therefore it can be assumed that the mutant exhibits similar growth behaviour to the wild-type. Moreover, changes in protein content were analysed, in conditions where the hydrogenase activity is favoured, revealing that 17 proteins had significant differential fold changes. These proteins are 
mainly related to the redox and energy state of the cells. Twelve proteins were more abundant in the mutant, including one of the possible transcription regulators of the bidirectional hydrogenase of Synechocystis. Overall, the functions of the proteins exhibiting different relative levels correlate with the proposed roles of the bidirectional hydrogenase in dark fermentation and photosynthesis (acting as an electron valve), as well as a role in the maintenance of cell homeostasis under specific conditions (transition states). In addition, transcription studies were performed to assess the patterns of 12 genes coding for proteins showing differential abundance. From this analysis, six genes exhibited significant differences in transcript levels following the same pattern as the protein abundance, with the exception of $p s b Y$ and $p e t B$ that showed an inverse trend. Altogether, these results indicate an adjustment in the metabolism of the $\Delta$ hoxYH mutant allowing growth at similar rates to the wild-type and reflecting the plasticity and metabolic adaptability of Synechocystis. Finally, this study suggests that the Synechocystis $\Delta$ hoxYH mutant is robust and can be used as a photoautotrophic chassis for the integration of synthetic devices to fulfil specific purposes, namely hydrogen production.

\section{ACKNOWLEDGEMENTS}

This work was financially supported by EU FP6-NEST-2005-Path-SYN project BioModularH2 (contract no. 043340); Fundação para a Ciência e a Tecnologia (SFRH/BD/36378/2007, SFRH/BPD/64095/2009, PTDC/ BIA-MIC/100370/2008); European Science Foundation (III Quadro Comunitário de Apoio), COMPETE - Programa Operacional Factores de Competitividade na sua componente FEDER; Acções Integradas Luso-Britânicas, Treaty of Windsor Programme 2010-11 (Processo B18/10); Engineering and Physical Sciences Research Council (EP/ E036252/1), under the ChELSI initiative; Generalitat Valenciana grant BFPI/2007/283; and MICINN project ArtBioCom (TIN2009-12359). The authors are grateful to Dr Alan Dunbar (Chemical and Biological Engineering, University of Sheffield) and Dr Saw Ow Yen (Chemical and Biological Engineering, University of Sheffield) for helpful discussion. The authors would also like to thank the 'National BioResource Project (NIG, Japan): E. coli' for providing the plasmid pK18mobsacB.

\section{REFERENCES}

Abed, R. M., Dobretsov, S. \& Sudesh, K. (2009). Applications of cyanobacteria in biotechnology. J Appl Microbiol 106, 1-12.

Agafonov, D. E., Kolb, V. A. \& Spirin, A. S. (2001). Ribosomeassociated protein that inhibits translation at the aminoacyl-tRNA binding stage. EMBO Rep 2, 399-402.

Ananyev, G., Carrieri, D. \& Dismukes, G. C. (2008). Optimization of metabolic capacity and flux through environmental cues to maximize hydrogen production by the cyanobacterium "Arthrospira (Spirulina) maxima". Appl Environ Microbiol 74, 6102-6113.

Angermayr, S. A., Hellingwerf, K. J., Lindblad, P. \& Teixeira de Mattos, M. J. (2009). Energy biotechnology with cyanobacteria. Curr Opin Biotechnol 20, 257-263.

Antal, T. K. \& Lindblad, P. (2005). Production of $\mathrm{H}_{2}$ by sulphurdeprived cells of the unicellular cyanobacteria Gloeocapsa alpicola and
Synechocystis sp. PCC 6803 during dark incubation with methane or at various extracellular pH. J Appl Microbiol 98, 114-120.

Antal, T. K., Oliveira, P. \& Lindblad, P. (2006). The bidirectional hydrogenase in the cyanobacterium Synechocystis sp. strain PCC 6803. Int J Hydrogen Energy 31, 1439-1444.

Appel, J. \& Schulz, R. (1996). Sequence analysis of an operon of a $\mathrm{NAD}(\mathrm{P})$-reducing nickel hydrogenase from the cyanobacterium Synechocystis sp. PCC 6803 gives additional evidence for direct coupling of the enzyme to $\mathrm{NAD}(\mathrm{P}) \mathrm{H}$-dehydrogenase (complex I). Biochim Biophys Acta 1298, 141-147.

Appel, J. \& Schulz, R. (1998). Hydrogen metabolism in organisms with oxygenic photosynthesis: hydrogenases as important regulatory devices for a proper redox poising? J Photochem Photobiol B 47, 1-11.

Appel, J., Phunpruch, S. \& Schulz, R. (1999). Hydrogenase(s) in Synechocystis - tools for Photohydrogen Production? In BioHydrogen, pp. 189-196. Edited by O. R. Zaborsky, J. R. Benemann, T. Matsunaga, J. Miyake \& A. San Pietro. US: Springer.

Appel, J., Phunpruch, S., Steinmüller, K. \& Schulz, R. (2000). The bidirectional hydrogenase of Synechocystis sp. PCC 6803 works as an electron valve during photosynthesis. Arch Microbiol 173, 333-338.

Barrios-Llerena, M. E., Chong, P. K., Gan, C. S., Snijders, A. P. L., Reardon, K. F. \& Wright, P. C. (2006). Shotgun proteomics of cyanobacteria-applications of experimental and data-mining techniques. Brief Funct Genomics Proteomics 5, 121-132.

Bashor, C. J., Horwitz, A. A., Peisajovich, S. G. \& Lim, W. A. (2010). Rewiring cells: synthetic biology as a tool to interrogate the organizational principles of living systems. Annu Rev Biophys 39, 515-537.

Bhaya, D., Vaulot, D., Amin, P., Takahashi, A. W. \& Grossman, A. R. (2000). Isolation of regulated genes of the cyanobacterium Synechocystis sp. strain PCC 6803 by differential display. J Bacteriol 182, 5692-5699.

Bothe, H., Schmitz, O., Yates, M. G. \& Newton, W. E. (2010a). Nitrogen fixation and hydrogen metabolism in cyanobacteria. Microbiol Mol Biol Rev 74, 529-551.

Bothe, H., Tripp, H. J. \& Zehr, J. P. (2010b). Unicellular cyanobacteria with a new mode of life: the lack of photosynthetic oxygen evolution allows nitrogen fixation to proceed. Arch Microbiol 192, 783-790.

Brand, S. N., Tan, X. \& Widger, W. R. (1992). Cloning and sequencing of the petBD operon from the cyanobacterium Synechococcus sp. PCC 7002. Plant Mol Biol 20, 481-491.

Burja, A. M., Banaigs, B., Abou-Mansour, E., Burgess, J. G. \& Wright, P. C. (2001). Marine cyanobacteria - a prolific source of natural products. Tetrahedron 57, 9347-9377.

Carrieri, D., Wawrousek, K., Eckert, C., Yu, J. \& Maness, P.-C. (2011). The role of the bidirectional hydrogenase in cyanobacteria. Bioresour Technol 102, 8368-8377.

Chong, P. K., Gan, C. S., Pham, T. K. \& Wright, P. C. (2006). Isobaric tags for relative and absolute quantitation (iTRAQ) reproducibility: Implication of multiple injections. J Proteome Res 5, 1232-1240.

Cournac, L., Mus, F., Bernard, L., Guedeney, G., Vignais, P. \& Peltier, G. (2002). Limiting steps of hydrogen production in Chlamydomonas reinhardtii and Synechocystis PCC 6803 as analysed by light-induced gas exchange transients. Int J Hydrogen Energy 27, 1229-1237.

Cournac, L., Guedeney, G., Peltier, G. \& Vignais, P. M. (2004). Sustained photoevolution of molecular hydrogen in a mutant of Synechocystis sp. strain PCC 6803 deficient in the type I NADPHdehydrogenase complex. J Bacteriol 186, 1737-1746.

Cramer, W. A., Martinez, S. E., Furbacher, P. N., Huang, D. \& Smith, J. L. (1994). The cytochrome $b_{6} f$ complex. Curr Opin Struct Biol 4, $536-544$. 
Dembitsky, V. M. (2006). Anticancer activity of natural and synthetic acetylenic lipids. Lipids 41, 883-924.

Devillers, J., Doré, J. C., Guyot, M., Poroikov, V., Gloriozova, T., Lagunin, A. \& Filimonov, D. (2007). Prediction of biological activity profiles of cyanobacterial secondary metabolites. SAR QSAR Environ Res 18, 629-643.

Dubrac, S. \& Touati, D. (2000). Fur positive regulation of iron superoxide dismutase in Escherichia coli: functional analysis of the sodB promoter. J Bacteriol 182, 3802-3808.

Elias, J. E. \& Gygi, S. P. (2007). Target-decoy search strategy for increased confidence in large-scale protein identifications by mass spectrometry. Nat Methods 4, 207-214.

Endy, D. (2005). Foundations for engineering biology. Nature 438, 449-453.

Fernández de Henestrosa, A. R., Ogi, T., Aoyagi, S., Chafin, D., Hayes, J. J., Ohmori, H. \& Woodgate, R. (2000). Identification of additional genes belonging to the LexA regulon in Escherichia coli. Mol Microbiol 35, 1560-1572.

Ferreira, D., Pinto, F., Moradas-Ferreira, P., Mendes, M. V. \& Tamagnini, P. (2009). Transcription profiles of hydrogenases related genes in the cyanobacterium Lyngbya majuscula CCAP 1446/4. BMC Microbiol 9, 67.

Gan, C. S., Reardon, K. F. \& Wright, P. C. (2005). Comparison of protein and peptide prefractionation methods for the shotgun proteomic analysis of Synechocystis sp. PCC 6803. Proteomics 5, 2468-2478.

Gan, C. S., Chong, P. K., Pham, T. K. \& Wright, P. C. (2007). Technical, experimental, and biological variations in isobaric tags for relative and absolute quantitation (iTRAQ). J Proteome Res 6, 821-827.

Gómez-García, M. R., Losada, M. \& Serrano, A. (2003). Concurrent transcriptional activation of $p p a$ and $p p x$ genes by phosphate deprivation in the cyanobacterium Synechocystis sp. strain PCC 6803. Biochem Biophys Res Commun 302, 601-609.

Gutekunst, K., Phunpruch, S., Schwarz, C., Schuchardt, S., SchulzFriedrich, R. \& Appel, J. (2005). LexA regulates the bidirectional hydrogenase in the cyanobacterium Synechocystis sp. PCC 6803 as a transcription activator. Mol Microbiol 58, 810-823.

Gutthann, F., Egert, M., Marques, A. \& Appel, J. (2007). Inhibition of respiration and nitrate assimilation enhances photohydrogen evolution under low oxygen concentrations in Synechocystis sp. PCC 6803. Biochim Biophys Acta 1767, 161-169.

Hall, H. K. \& Foster, J. W. (1996). The role of Fur in the acid tolerance response of Salmonella typhimurium is physiologically and genetically separable from its role in iron acquisition. J Bacteriol 178, 5683-5691.

Hihara, Y., Muramatsu, M., Nakamura, K. \& Sonoike, K. (2004). A cyanobacterial gene encoding an ortholog of Pirin is induced under stress conditions. FEBS Lett 574, 101-105.

Johnson, M., Zaretskaya, I., Raytselis, Y., Merezhuk, Y., McGinnis, S. \& Madden, T. L. (2008). NCBI BLAST: a better web interface. Nucleic Acids Res 36 (Web Server issue), W5-W9. doi:10.1093/ dnares/10.5.221

Kaneko, T., Sato, S., Kotani, H., Tanaka, A., Asamizu, E., Nakamura, Y., Miyajima, N., Hirosawa, M., Sugiura, M. \& other authors (1996). Sequence analysis of the genome of the unicellular cyanobacterium Synechocystis sp. strain PCC6803. II. Sequence determination of the entire genome and assignment of potential protein-coding regions. DNA Res 3, 109-136.

Kaneko, T., Nakamura, Y., Sasamoto, S., Watanabe, A., Kohara, M., Matsumoto, M., Shimpo, S., Yamada, M. \& Tabata, S. (2003). Structural analysis of four large plasmids harboring in a unicellular cyanobacterium, Synechocystis sp. PCC 6803. DNA Res 10, 221-228.
Kanematsu, S. \& Sato, S. (2008). Cloning of Fe-superoxide dismutase gene from the diazotroph Azotobacter vinelandii and the stimulation of its expression under anaerobic conditions in Escherichia coli. Bull Minamikyushu Univ 38A, 7-18.

Kawakami, K., Iwai, M., Ikeuchi, M., Kamiya, N. \& Shen, J.-R. (2007). Location of PsbY in oxygen-evolving photosystem II revealed by mutagenesis and X-ray crystallography. FEBS Lett 581, 4983-4987.

Keasling, J. D. (2008). Synthetic biology for synthetic chemistry. ACS Chem Biol 3, 64-76.

Khalil, A. S. \& Collins, J. J. (2010). Synthetic biology: applications come of age. Nat Rev Genet 11, 367-379.

Kim, J.-H. \& Suh, K. H. (2005). Light-dependent expression of superoxide dismutase from cyanobacterium Synechocystis sp. strain PCC 6803. Arch Microbiol 183, 218-223.

Kiss, É., Kós, P. B. \& Vass, I. (2009). Transcriptional regulation of the bidirectional hydrogenase in the cyanobacterium Synechocystis 6803. J Biotechnol 142, 31-37.

Kobayashi, M., Ishizuka, T., Katayama, M., Kanehisa, M., BhattacharyyaPakrasi, M., Pakrasi, H. B. \& Ikeuchi, M. (2004). Response to oxidative stress involves a novel peroxiredoxin gene in the unicellular cyanobacterium Synechocystis sp. PCC 6803. Plant Cell Physiol 45, 290-299.

Koksharova, O. A. \& Wolk, C. P. (2002). Genetic tools for cyanobacteria. Appl Microbiol Biotechnol 58, 123-137.

Kornberg, A. (1962). On the metabolic significance of phosphorolytic and pyrophosphorolytic reactions. In Horizons in Biochemistry: Albert Szent-Györgyi Dedicatory Volume, pp. 251-264. Edited by M. Kasha \& B. Pullman. New York: Academic Press, Inc.

Krenn, B. E., Strotmann, H., Van Walraven, H. S., Scholts, M. J. C. \& Kraayenhof, R. (1997). The ATP synthase $\gamma$ subunit provides the primary site of activation of the chloroplast enzyme: experiments with a chloroplast-like Synechocystis 6803 mutant. Biochem J 323, 841-845.

Kruip, J., Nixon, P. J., Osiewacz, H. D. \& Rögner, M. (1994). Nucleotide sequence of the pet $B$ gene encoding cytochrome $b_{6}$ from the mesophilic cyanobacterium Synechocystis PCC 6803: implications for evolution and function. Biochim Biophys Acta 1188, 443-446.

Kunert, A., Vinnemeier, J., Erdmann, N. \& Hagemann, M. (2003). Repression by Fur is not the main mechanism controlling the ironinducible isiAB operon in the cyanobacterium Synechocystis sp. PCC 6803. FEMS Microbiol Lett 227, 255-262.

Leitão, E., Pereira, S., Bondoso, J., Ferreira, D., Pinto, F., MoradasFerreira, P. \& Tamagnini, P. (2006). Genes involved in the maturation of hydrogenase(s) in the nonheterocystous cyanobacterium Lyngbya majuscula CCAP 1446/4. Int J Hydrogen Energy 31, 1469-1477.

Li, H., Singh, A. K., Mclntyre, L. M. \& Sherman, L. A. (2004). Differential gene expression in response to hydrogen peroxide and the putative PerR regulon of Synechocystis sp. strain PCC 6803. J Bacteriol 186, 3331-3345.

Li, S., Xu, M. \& Su, Z. (2010). Computational analysis of LexA regulons in Cyanobacteria. BMC Genomics 11, 527.

Lindahl, M. \& Florencio, F. J. (2003). Thioredoxin-linked processes in cyanobacteria are as numerous as in chloroplasts, but targets are different. Proc Natl Acad Sci U S A 100, 16107-16112.

Little, J. W. \& Mount, D. W. (1982). The SOS regulatory system of Escherichia coli. Cell 29, 11-22.

Ludwig, M., Schulz-Friedrich, R. \& Appel, J. (2006). Occurrence of hydrogenases in cyanobacteria and anoxygenic photosynthetic bacteria: implications for the phylogenetic origin of cyanobacterial and algal hydrogenases. J Mol Evol 63, 758-768.

Masukawa, H., Mochimaru, M. \& Sakurai, H. (2002). Disruption of the uptake hydrogenase gene, but not of the bidirectional hydrogenase 
gene, leads to enhanced photobiological hydrogen production by the nitrogen-fixing cyanobacterium Anabaena sp. PCC 7120. Appl Microbiol Biotechnol 58, 618-624.

McIntosh, C. L., Germer, F., Schulz, R., Appel, J. \& Jones, A. K. (2011). The [NiFe]-hydrogenase of the cyanobacterium Synechocystis sp. PCC 6803 works bidirectionally with a bias to $\mathrm{H}_{2}$ production. J Am Chem Soc 133, 11308-11319.

McNeely, K., Xu, Y., Bennette, N., Bryant, D. A. \& Dismukes, G. C. (2010). Redirecting reductant flux into hydrogen production via metabolic engineering of fermentative carbon metabolism in a cyanobacterium. Appl Environ Microbiol 76, 5032-5038.

Moisander, P. H., Beinart, R. A., Hewson, I., White, A. E., Johnson, K. S., Carlson, C. A., Montoya, J. P. \& Zehr, J. P. (2010). Unicellular cyanobacterial distributions broaden the oceanic $\mathrm{N}_{2}$ fixation domain. Science 327, 1512-1514.

Motohashi, K., Kondoh, A., Stumpp, M. T. \& Hisabori, T. (2001). Comprehensive survey of proteins targeted by chloroplast thioredoxin. Proc Natl Acad Sci U S A 98, 11224-11229.

Nakamura, Y., Kaneko, T. \& Tabata, S. (2000). CyanoBase, the genome database for Synechocystis sp. strain PCC6803: status for the year 2000. Nucleic Acids Res 28, 72.

Navarro, F., Martín-Figueroa, E. \& Florencio, F. J. (2000). Electron transport controls transcription of the thioredoxin gene $(\operatorname{tr} x A)$ in the cyanobacterium Synechocystis sp. PCC 6803. Plant Mol Biol 43, 23-32.

Nefedova, L. N., Mel'nik, V. A. \& Babykin, M. M. (2003). Mutants of cyanobacterium Synechocystis sp. PCC 6803 with insertional inactivation of the $\operatorname{sodB}$ gene encoding Fe-superoxide dismutase. Russ J Genet 39, 386-389.

Noirel, J., Sanguinetti, G. \& Wright, P. C. (2008). Identifying differentially expressed subnetworks with MMG. Bioinformatics 24, 2792-2793.

Noirel, J., Ow, S. Y., Sanguinetti, G. \& Wright, P. C. (2009). Systems biology meets synthetic biology: a case study of the metabolic effects of synthetic rewiring. Mol Biosyst 5, 1214-1223.

Noirel, J., Evans, C., Salim, M., Mukherjee, J., Ow, S. Y., Pandhal, J., Pham, T. K., Biggs, C. A. \& Wright, P. C. (2011). Methods in quantitative proteomics: setting iTRAQ on the right track. Curr Proteomics 8, 17-30.

Nunoshiba, T., Obata, F., Boss, A. C., Oikawa, S., Mori, T., Kawanishi, S. \& Yamamoto, K. (1999). Role of iron and superoxide for generation of hydroxyl radical, oxidative DNA lesions, and mutagenesis in Escherichia coli. J Biol Chem 274, 34832-34837.

Oliveira, P. (2008). Regulation of the Cyanobacterial Bidirectional Hydrogenase, pp. 63. Uppsala: Acta Universitatis Upsaliensis.

Oliveira, P. \& Lindblad, P. (2005). LexA, a transcription regulator binding in the promoter region of the bidirectional hydrogenase in the cyanobacterium Synechocystis sp. PCC 6803. FEMS Microbiol Lett 251, 59-66.

Oliveira, P. \& Lindblad, P. (2008). An AbrB-Like protein regulates the expression of the bidirectional hydrogenase in Synechocystis sp. strain PCC 6803. J Bacteriol 190, 1011-1019.

Oliveira, P. \& Lindblad, P. (2009). Transcriptional regulation of the cyanobacterial bidirectional Hox-hydrogenase. Dalton Trans (45), 9990-9996.

Osanai, T., Kanesaki, Y., Nakano, T., Takahashi, H., Asayama, M., Shirai, M., Kanehisa, M., Suzuki, I., Murata, N. \& Tanaka, K. (2005). Positive regulation of sugar catabolic pathways in the cyanobacterium Synechocystis sp. PCC 6803 by the group $2 \sigma$ factor sigE. J Biol Chem 280, 30653-30659.

Ow, S. Y. \& Wright, P. C. (2009). Current trends in high throughput proteomics in cyanobacteria. FEBS Lett 583, 1744-1752.
Ow, S. Y., Salim, M., Noirel, J., Evans, C., Rehman, I. \& Wright, P. C. (2009). iTRAQ underestimation in simple and complex mixtures: "the good, the bad and the ugly". J Proteome Res 8, 5347-5355.

Padan, E., Bibi, E., Ito, M. \& Krulwich, T. A. (2005). Alkaline pH homeostasis in bacteria: new insights. Biochim Biophys Acta 1717, 6788.

Patterson-Fortin, L. M., Colvin, K. R. \& Owttrim, G. W. (2006). A LexA-related protein regulates redox-sensitive expression of the cyanobacterial RNA helicase, crhR. Nucleic Acids Res 34, 34463454.

Pérez-Pérez, M. E., Martín-Figueroa, E. \& Florencio, F. J. (2009). Photosynthetic regulation of the cyanobacterium Synechocystis sp. PCC 6803 thioredoxin system and functional analysis of $\operatorname{TrxB}(\operatorname{Trx} \mathrm{x})$ and TrxQ (Trx y) thioredoxins. Mol Plant 2, 270-283.

Pham, T. K., Roy, S., Noirel, J., Douglas, I., Wright, P. C. \& Stafford, G. P. (2010). A quantitative proteomic analysis of biofilm adaptation by the periodontal pathogen Tannerella forsythia. Proteomics 10, 3130-3141.

Pósfai, G., Plunkett, G., III, Fehér, T., Frisch, D., Keil, G. M., Umenhoffer, K., Kolisnychenko, V., Stahl, B., Sharma, S. S. \& other authors (2006). Emergent properties of reduced-genome Escherichia coli. Science 312, 1044-1046.

Reidegeld, K. A., Eisenacher, M., Kohl, M., Chamrad, D., Körting, G., Blüggel, M., Meyer, H. E. \& Stephan, C. (2008). An easy-to-use Decoy Database Builder software tool, implementing different decoy strategies for false discovery rate calculation in automated MS/MS protein identifications. Proteomics 8, 1129-1137.

Sakthivel, K., Watanabe, T. \& Nakamoto, H. (2009). A small heatshock protein confers stress tolerance and stabilizes thylakoid membrane proteins in cyanobacteria under oxidative stress. Arch Microbiol 191, 319-328.

Sambrook, J. \& Russell, D. W. (2001). Molecular Cloning: a Laboratory Manual. New York, USA: Cold Spring Harbor Laboratory Press.

Sanguinetti, G., Noirel, J. \& Wright, P. C. (2008). MMG: a probabilistic tool to identify submodules of metabolic pathways. Bioinformatics 24, 1078-1084.

Sato, S., Shimoda, Y., Muraki, A., Kohara, M., Nakamura, Y. \& Tabata, S. (2007). A large-scale protein-protein interaction analysis in Synechocystis sp. PCC6803. DNA Res 14, 207-216.

Schäfer, A., Tauch, A., Jäger, W., Kalinowski, J., Thierbach, G. \& Pühler, A. (1994). Small mobilizable multi-purpose cloning vectors derived from the Escherichia coli plasmids pK18 and pK19: selection of defined deletions in the chromosome of Corynebacterium glutamicum. Gene 145, 69-73.

Schmitt, W. A., Jr \& Stephanopoulos, G. (2003). Prediction of transcriptional profiles of Synechocystis PCC6803 by dynamic autoregressive modeling of DNA microarray data. Biotechnol Bioeng 84, 855-863.

Schmitz, O. \& Bothe, H. (1996). The diaphorase subunit HoxU of the bidirectional hydrogenase as electron transferring protein in cyanobacterial respiration? Naturwissenschaften 83, 525-527.

Schütz, K., Happe, T., Troshina, O., Lindblad, P., Leitão, E., Oliveira, P. \& Tamagnini, P. (2004). Cyanobacterial $\mathrm{H}_{2}$ production - a comparative analysis. Planta 218, 350-359.

Sharma, S. S., Blattner, F. R. \& Harcum, S. W. (2007a). Recombinant protein production in an Escherichia coli reduced genome strain. Metab Eng 9, 133-141.

Sharma, S. S., Campbell, J. W., Frisch, D., Blattner, F. R. \& Harcum, S. W. (2007b). Expression of two recombinant chloramphenicol acetyltransferase variants in highly reduced genome Escherichia coli strains. Biotechnol Bioeng 98, 1056-1070. 
Shcolnick, S., Summerfield, T. C., Reytman, L., Sherman, L. A. \& Keren, N. (2009). The mechanism of iron homeostasis in the unicellular cyanobacterium Synechocystis sp. PCC 6803 and its relationship to oxidative stress. Plant Physiol 150, 2045-2056.

Sherman, D. M., Troyan, T. A. \& Sherman, L. A. (1994). Localization of membrane proteins in the cyanobacterium Synechococcus sp. PCC7942 (radial asymmetry in the photosynthetic complexes). Plant Physiol 106, 251-262.

Sjöholm, J., Oliveira, P. \& Lindblad, P. (2007). Transcription and regulation of the bidirectional hydrogenase in the cyanobacterium Nostoc sp. strain PCC 7120. Appl Environ Microbiol 73, 5435-5446.

Stal, L. J. \& Moezelaar, R. (1997). Fermentation in cyanobacteria. FEMS Microbiol Rev 21, 179-211.

Stanier, R. Y., Kunisawa, R., Mandel, M. \& Cohen-Bazire, G. (1971). Purification and properties of unicellular blue-green algae (order Chroococcales). Bacteriol Rev 35, 171-205.

Stroebel, D., Choquet, Y., Popot, J.-L. \& Picot, D. (2003). An atypical haem in the cytochrome $b_{6} f$ complex. Nature 426, 413-418.

Summerfield, T. C. \& Sherman, L. A. (2008). Global transcriptional response of the alkali-tolerant cyanobacterium Synechocystis sp. strain PCC 6803 to a pH 10 environment. Appl Environ Microbiol 74, 52765284.

Summerfield, T. C., Nagarajan, S. \& Sherman, L. A. (2011). Gene expression under low-oxygen conditions in the cyanobacterium Synechocystis sp. PCC 6803 demonstrates Hik31-dependent and -independent responses. Microbiology 157, 301-312.

Suzuki, I., Simon, W. J. \& Slabas, A. R. (2006). The heat shock response of Synechocystis sp. PCC 6803 analysed by transcriptomics and proteomics. J Exp Bot 57, 1573-1578.

Tamagnini, P., Troshina, O., Oxelfelt, F., Salema, R. \& Lindblad, P. (1997). Hydrogenases in Nostoc sp. strain PCC 73102, a strain lacking a bidirectional enzyme. Appl Environ Microbiol 63, 1801-1807.

Tamagnini, P., Costa, J. L., Almeida, L., Oliveira, M. J., Salema, R. \& Lindblad, P. (2000). Diversity of cyanobacterial hydrogenases, a molecular approach. Curr Microbiol 40, 356-361.

Tamagnini, P., Axelsson, R., Lindberg, P., Oxelfelt, F., Wünschiers, R. \& Lindblad, P. (2002). Hydrogenases and hydrogen metabolism of cyanobacteria. Microbiol Mol Biol Rev 66, 1-20.

Tamagnini, P., Leitão, E., Oliveira, P., Ferreira, D., Pinto, F., Harris, D. J., Heidorn, T. \& Lindblad, P. (2007). Cyanobacterial hydrogenases: diversity, regulation and applications. FEMS Microbiol Rev 31, 692720.

Thajuddin, N. \& Subramanian, G. (2005). Cyanobacterial biodiversity and potential applications in biotechnology. Curr Sci 89, 47-57.

Troshina, O., Serebryakova, L., Sheremetieva, M. \& Lindblad, P. (2002). Production of $\mathrm{H}_{2}$ by the unicellular cyanobacterium Gloeocapsa alpicola CALU 743 during fermentation. Int J Hydrogen Energy 27, 1283-1289.

Ushimaru, T., Nishiyama, Y., Hayashi, H. \& Murata, N. (2002). No coordinated transcriptional regulation of the sod-kat antioxidative system in Synechocystis sp. PCC 6803. J Plant Physiol 159, 805-807.

van der Oost, J., Bulthuis, B. A., Feitz, S., Krab, K. \& Kraayenhof, R. (1989). Fermentation metabolism of the unicellular cyanobacterium Cyanothece PCC 7822. Arch Microbiol 152, 415-419.

Vila-Sanjurjo, A., Schuwirth, B.-S., Hau, C. W. \& Cate, J. H. D. (2004). Structural basis for the control of translation initiation during stress. Nat Struct Mol Biol 11, 1054-1059.

Vinnemeier, J., Kunert, A. \& Hagemann, M. (1998). Transcriptional analysis of the $i s i A B$ operon in salt-stressed cells of the cyanobacterium Synechocystis sp. PCC 6803. FEMS Microbiol Lett 169, 323-330.

Williams, J. G. K. (1988). Construction of specific mutations in photosystem II photosynthetic reaction center by genetic engineering methods in Synechocystis 6803. Methods Enzymol 167, 766-778.

Xu, W. D. \& McFadden, B. A. (1997). Sequence analysis of plasmid pCC5.2 from cyanobacterium Synechocystis PCC 6803 that replicates by a rolling circle mechanism. Plasmid 37, 95-104.

Yadav, V. G. \& Stephanopoulos, G. (2010). Reevaluating synthesis by biology. Curr Opin Microbiol 13, 371-376.

Yang, X. Y. \& McFadden, B. A. (1993). A small plasmid, pCA2.4, from the cyanobacterium Synechocystis sp. strain PCC 6803 encodes a Rep protein and replicates by a rolling circle mechanism. J Bacteriol 175, 3981-3991.

Yang, X. Y. \& McFadden, B. A. (1994). The complete DNA sequence and replication analysis of the plasmid pCB2.4 from the cyanobacterium Synechocystis PCC 6803. Plasmid 31, 131-137.

Zhang, Z., Pendse, N. D., Phillips, K. N., Cotner, J. B. \& Khodursky, A. (2008). Gene expression patterns of sulfur starvation in Synechocystis sp. PCC 6803. BMC Genomics 9, 344.

Edited by: C.-C. Zhang 